\title{
Insect prophenoloxidase: the view beyond immunity
}

\section{Anrui Lu, Qiaoli Zhang, Jie Zhang, Bing Yang, Kai Wu, Wei Xie, Yun-Xia Luan and Erjun Ling*}

Key Laboratory of Insect Developmental and Evolutionary Biology, Institute of Plant Physiology and Ecology, Shanghai Institutes for Biological Sciences, Chinese Academy of Sciences, Shanghai, China

Edited by:

Raman Chandrasekar, Kansas State

University, USA

Reviewed by:

Luciana Lopes Guimarães,

Universidade Santa Cecilia, Brazil

Raman Chandrasekar, Kansas State

University, USA

\section{*Correspondence:}

Eriun Ling, Institute of Plant

Physiology and Ecology, 300 Feng

Lin Road, Shanghai 200032, China

e-mail: erjunling@sippe.ac.cn;

ejling@sibs.ac.cn
Insect prophenoloxidase (PPO) is an important innate immunity protein due to its involvement in cellular and humoral defense. It belongs to a group of type-3 copper-containing proteins that occurs in almost all organisms. Insect PPO has been studied for over a century, and the PPO activation cascade is becoming clearer. The insect PPO activation pathway incorporates several important proteins, including pattern-recognition receptors (PGRP, $\beta$ GRP, and C-type lectins), serine proteases, and serine protease inhibitors (serpins). Due to their complexity, PPO activation mechanisms vary among insect species. Activated phenoloxidase (PO) oxidizes phenolic molecules to produce melanin around invading pathogens and wounds. The crystal structure of Manduca sexta PPO shows that a conserved amino acid, phenylalanine (F), can block the active site pocket. During activation, this blocker must be dislodged or even cleaved at the N-terminal sequence to expose the active site pockets and allow substrates to enter. Thanks to the crystal structure of $M$. sexta PPO, some domains and specific amino acids that affect PPO activities have been identified. Further studies of the relationship between PPO structure and enzyme activities will provide an opportunity to examine other type-3 copper proteins, and trace when and why their various physiological functions evolved. Recent researches show that insect PPO has a relationship with neuron activity, longevity, feces melanization (phytophagous insects) and development, which suggests that it is time for us to look back on insect PPO beyond the view of immunity in this review.

Keywords: insect, prophenoloxidase, type-3 copper proteins, protein structure, melanization

\section{INTRODUCTION}

Type-3 copper proteins have two copper ions and three histidines $(\mathrm{H})$ in each active site pocket (Ashida and Brey, 1997; Aguilera et al., 2013). This group of proteins is distributed extensively among almost all organisms, including vertebrates, invertebrates, plants, and microbes (Aguilera et al., 2013). Type-3 copper proteins from different organisms are named differently; e.g., tyrosinase in mammals and microbes, prophenoloxidase (PPO) in insects and crabs, polyphenol oxidase (also termed as PPO) in plants, and hemocyanin in arthropods (Cerenius et al., 2008; Aguilera et al., 2013). Each type-3 copper protein has a different physiological function. Mammalian tyrosinase activity is closely related to skin and hair color, and loss of tyrosinase activity in humans is the direct cause of albinism and leucoderma (Oetting and King, 1999; Kirkwood, 2009). Activation of plant polyphenol oxidase induces the browning of food, decreasing its qualities (Aquino-Bolaños and Mercado-Silva, 2004). However, polyphenol oxidase can also affect the production of tea volatiles (Harbowy and Balentine, 1997). Arthropod hemocyanin mainly transfers oxygen in the hemolymph (van Holde and Miller, 1995), while tyrosinase in microbes is positively related to pathogenicity (Mayer, 2006; Shang et al., 2012) and, in insects and other arthropods, $\mathrm{PPO}$ is an important innate immunity protein (Ashida and Brey, 1997; Cerenius et al., 2008; Kanost and Gorman, 2008). Insect hemolymph melanization induced by the PPO was first recorded in 1898 (Biedermann and Moritz, 1898). Over the last three to four decades, many laboratories have worked cooperatively on the PPO activation pathway and its regulation (Ashida and Brey, 1997; Cerenius et al., 2008; Kanost and Gorman, 2008), and it is now clear that PPO activation occurs through a cascade of patterns-recognition proteins, serine proteases, and serine protease inhibitors (serpin) after initial pathogen detection (Ashida and Brey, 1997; Cerenius et al., 2008; Kanost and Gorman, 2008). In some insects, serine protease homologs (SPH) are involved in PPO activation (Ross et al., 2003; Yu et al., 2003). In addition, insect PPO is also responsible for wound healing and hemolymph clotting (Lai et al., 2002; Ramet et al., 2002; Galko and Krasnow, 2004; Karlsson et al., 2004). However, the recent knock-down and knock-out of PPO in Tribolium castaneum and Drosophila melanogaster indicate that insect $\mathrm{PPO}$ does not determine cuticle sclerotization (Shao et al., 2012; Binggeli et al., 2014).

In insects, the innate immune system is composed mainly of cellular and humoral immunity (Strand, 2008). Cellular immunity includes phagocytosis of small invading microbes and the encapsulation of large parasites by circulating hemocytes (Lavine and Strand, 2002; Strand, 2008). Humoral immunity is induced by humoral antibacterial peptides (AMP) produced via the Toll and/or immune deficiency (Imd) pathways, as well as many other immunity proteins (Lemaitre and Hoffmann, 2007). PPO is a humoral protein that can induce melanization around invading pathogens after activation, and induces cellular and humoral immunity simultaneously (Lemaitre and 
Hoffmann, 2007). Intermediates produced in the melanization process can kill bacteria directly (Zhao et al., 2007). When PPO was knocked down via RNAi, invertebrate animals were easily infected by pathogenic bacteria and viruses (Liu et al., 2007; Paria et al., 2013). After knock-down of PPO in Aeromonas hydrophila, phagocytosis and nodule formation were reduced and, eventually, bacteria in the hemolymph multiplied and caused mortality (Liu et al., 2007). When D. melanogaster PPO1 and PPO2 $\left(\mathrm{DmPPO} 1\right.$ and DmPPO2) were deleted, the mutants $\left(\mathrm{PPO}^{\Delta}{ }^{\Delta}\right.$, $\mathrm{PPO}^{\Delta}$ ) were more susceptible to infection by gram-positive bacteria and fungi (Binggeli et al., 2014). Thus, PPO is an important immunity protein in both insects and other invertebrates, as has been reviewed in several studies (Ashida and Brey, 1997; Cerenius et al., 2008; Kanost and Gorman, 2008; González-Santoyo and Córdoba-Aguilar, 2012). In this review, we focus on information beyond the involvement of PPO in immune responses, mainly in insects and some other invertebrates.

\section{DISTRIBUTION OF PPO}

In insects, circulating hemocytes has been viewed as the only source of PPO (Ashida and Brey, 1997). In the silkworm Bombyx mori (B. mori) and other Lepidoptera, oenocytoids produce PPO (Strand, 2008; Liu et al., 2013), whereas in D. melanogaster, crystal cells produce PPO (Rizki et al., 1985). However, other types of hemocyte may have PPO in insects and other invertebrates; for example, in Carcinus maenas, granulocytes have PPO (Söderhäll and Smith, 1983). Recent work indicates that some prohemocytes, granulocytes and plasmatocytes also have PPO in B. mori (Ling et al., 2005), and PPO-positive hemocytes have been identified in B. mori hematopoietic organs (Wang et al., 2010). Staining reveals that some granulocytes and spherulocytes in Manduca sexta also have PPO (Ling and Yu, 2005). Moreover, immunostaining of living hemocytes using antibodies against $M$. sexta PPO revealed that PPO binds to the membranes of granulocytes and spherulocytes, but not to those of oenocytoids (Ling and Yu, 2005). In Culex pipiens quinquefasciatus, oenocytoids, prohemocytes, and granulocytes may be PPO-positive, but depend on the developmental stage and even the extent of blood feeding (Wang et al., 2011). Thus, the distribution of PPO protein in hemocytes is not limited to one type. Since it wasn't accomplished so far to colocalize the levels of in situ transcription and PO activity (both activation and staining) on the same cells because they require different assays, it is difficult to conclusively show that PPOpositive hemocytes can produce PPO. However, plasma PPO contamination can be ruled out because anticoagulant buffers have been used in some studies. Furthermore, not all hemocytes were positively stained, based on simultaneous observations using a microscope.

A recent study showed that epidermal cells in the hindgut of B. mori also produce PPO (Shao et al., 2012); the authors used various techniques to show that the cells contained signals associated with PPO proteins, transcription, and activity. To prevent contamination, circulating hemocytes were pre-labeled via phagocytosis of injected fluorescent beads. However, no fluorescent beads were found in the hindgut, which indicates that any PPO-positive cells present in the midgut were not hemocytes. The authors also used lysozyme, an immunity protein produced in response to an immune challenge, as a probe to show that there is no direct physical exchange between the hindgut and plasma. Therefore, PPO in the hindgut was from neither hemocytes nor plasma contamination. The wild-type D. melanogaster larval hindgut was also positively stained (Shao et al., 2012), as described above. However, when both DmPPO1 and DmPPO2 $\left(\mathrm{PPO}^{\Delta}{ }^{\Delta}, \mathrm{PPO}^{\Delta}{ }^{\Delta}\right.$ ) were deleted (Binggeli et al., 2014), the larval hindguts of those mutants were not positively stained ( $\mathrm{Lu}$, personal observations). All species of insects assayed in the study had PPO in their hindguts according to the staining results (Shao et al., 2012).

PPO was also found in other tissues. For example, wing discs dissected from B. mori larvae can release PPO into the culture medium. However, PPO-positive cells in wing disc cavities might derive from the attached hematopoietic organ (Diao et al., 2012). Since wing discs are physically connected with the hematopoietic organ via many small tubes (Ling et al., 2006), some hemocytes may be accidentally released into the wing discs when PPO is released. PPO has also been identified in the hind wing of $T$. castaneum by MALDI/TOF (Dittmer et al., 2012). Insect cuticle has PPO (Ashida and Brey, 1997). No PPO mRNA signals were detected in the silkworm epidermal cells, and the authors concluded that cuticular PPO was transferred from the hemolymph (Asano and Ashida, 2001). Biochemical assays indicate that cuticular PPO is modified during its transfer from hemolymph to cuticle (Asano and Ashida, 2001). According to proteomics studies, PPO also occurs in some other tissues, including the silk gland, trachea, and adult scales (Fu et al., 2011; Dong et al., 2013).

PPO has no signal peptides (Ashida and Brey, 1997; Cerenius et al., 2008; Kanost and Gorman, 2008). Thus, it is thought to be released from hemocytes after lysis (Ashida and Brey, 1997), which is regulated by the JNK pathway in D. melanogaster (Bidla et al., 2007). Eicosanoids can also regulate PPO releasing from oenocytoids (Shrestha and Kim, 2008). However, the mechanism underlying PPO is releasing from hindgut cells is at present unclear; it may be regulated by an unknown mechanism.

\section{PPO DETECTION}

Immunostaining and in situ hybridization is the best methods of determining protein or transcript levels when searching for cellular proteins. For example, immunostaining and in situ hybridization of $B$. mori and M. sexta showed that their oenocytoids produce PPO (Iwama and Ashida, 1986; Jiang et al., 1997). Antibodies that can detect PPO in one insect species may not cross-identify PPO in others. However, there are several simple methods for detecting insect PPO in cells and tissues. Insect PPO can be activated by many cationic or anionic detergents and alcohols (e.g., methanol, ethanol, and 2-propanol) via unknown mechanisms (Ashida and Brey, 1997). Ethanol can activate PPO even within cells and tissues, and PPO-positive cells appear if the substrates are subsequently replaced (Ling et al., 2005). Using this method, new types of PPO-positive hemocytes and tissues have been identified without using the immunostaining method (Ling and Yu, 2005; Ling et al., 2005; Diao et al., 2012; Shao et al., 2012). This method can also be used to detect PPO in native gels; for example, DmPPO1 and DmPPO2 appear as different bands on the same native gel (Asano and Takebuchi, 
2009). A native gel assay showed that PPO was released separately from cultured larval wing discs and hindguts (Diao et al., 2012; Shao et al., 2012). After deletion of one of the two disulfides in DmPPO1, the enzyme activities of mutants decreased significantly on the same native gel (Lu et al., 2014b). In other studies, DmPPO1 was over-expressed in S2 cells for $48 \mathrm{~h}$ with and without $\mathrm{Cu}^{2+}$ added (Chen et al., 2012; Liu et al., 2012). When $\mathrm{Cu}^{2+}$ was absent, PPO did not appear unless the native gel was pre-incubated in a buffer containing $\mathrm{Cu}^{2+}$ and, compared to the treatment that included $\mathrm{Cu}^{2+}$, the two bands were shifted (Liu et al., 2012). This indicates that PPO expression and $\mathrm{Cu}^{2+}$ chelation into the active site pockets are independent processes. Two $\mathrm{Cu}^{2+}$ ions can significantly alter the electric charge of PPO, but this unique property would not have been found without resolution of the corresponding PPOs on a native gel. Besides PPO, enzymes such as laccase and peroxidase also oxidize some phenols to produce melanin (Kanost and Gorman, 2008). Therefore, it is necessary to identify such enzymes when a staining method based on enzyme activity is used. PPO is the only enzyme activated by ethanol (Shao et al., 2012). When their specific substrates and strong inhibitors are taken into considerations, identifying the enzyme responsible for the staining is relatively easy (Shao et al., 2012). Therefore, PPO can be quickly detected by taking advantage of its activation by ethanol and other detergents.

\section{EXPRESSION OF RECOMBINANT PPO IN EUKARYOTIC AND PROKARYOTIC CELLS}

Purification of native insect PPO is challenging since it is easily activated during preparations. However, studying its biochemical properties requires sufficient purified PPO. It may be helpful to produce recombinant PPO in this context. Spodoptera litura PPO (SlPPO) was also expressed in E. coli at $37^{\circ} \mathrm{C}$ (Rajagopal et al., 2005), but there was no solid evidence that the recombinant SIPPO had PO activity. In D. melanogaster, there are three PPO genes: DmPPO1 (CG5779), DmPPO2 (CG8193), and DmPPO3 (CG2952). Recently, three PPOs from D. melanogaster (DmPPO) were over-expressed in S2 cells, and all had PO activities if additional $\mathrm{Cu}^{2+}$ was added to the culture medium (Liu et al., 2012). By contrast, only DmPPO1 and DmPPO2 were expressed in wildtype D. melanogaster (Tang, 2009; Binggeli et al., 2014). Another study found that recombinant DmPPOs were expressed in E. coli at $16^{\circ} \mathrm{C}$, yielding soluble DmPPO (Li et al., 2012). These recombinant DmPPO proteins showed PO activity upon activation by cetylpyridinium chloride (CPC), ethanol, and serine protease. In an $E$. coli expression system, $\mathrm{Cu}^{2+}$ was not necessary during protein expression (Li et al., 2012), and its absence yielded apoPPO and avoided PPO activation during purification. Conversely, $\mathrm{Cu}^{2+}$ can be added to transform apo-PPO into holo-PPO for later PO activity assays. The expression of insect PPO in E. coli is helpful for understanding the relationship between its structure and enzyme activity (Chen et al., 2012; Lu et al., 2014b), and its activation in vitro (Lu et al., 2014a). The mosquito genome contains up to 10 PPO genes (Christophides et al., 2002; Waterhouse et al., 2007), and we expect that, in the future, these PPOs will be separated over-expressed to facilitate evaluations of their biochemical properties, and anti-bacterial and -malarial activities.

\section{PPO STRUCTURE AND ACTIVITIES}

Determination of the crystal structure of a protein is important for understanding its functions. The crystal structures of several type-3 copper proteins, including hemocyanins, catechol oxidase, and bacterial tyrosinase, have been determined (Gerdemann et al., 2002; Kusche et al., 2003; Sendovski et al., 2011), and that of MsPPO has also been determined using purified native $M$. sexta PPO (Li et al., 2009). The latter crystal structure shows that M. sexta PPO is a heterodimer with MsPPO1 and MsPPO2 formed back-to-back (Li et al., 2009). MsPPO has two copper atoms $(\mathrm{CuA}$ and $\mathrm{CuB})$ in the active site pocket and two disulfide bonds in each monomer, as predicted. A conserved Phe (F) residue called as the place holder occurs in the active site pocket before activation and is thought to block access to the substrate. When PPO is activated, this place holder must be removed from the active site pocket. When the blocking residue $\left(\mathrm{F}^{84}\right)$ in DmPPO3 was mutated into tryptophan $(\mathrm{W})$, which has a hydrophobic side chain, DmPPO3 $\left(\mathrm{W}^{84}\right)$ activity significantly decreased after being activated by ethanol (Chen et al., 2012).

DmPPO3 is unique to D. melanogaster. When D. melanogaster was infected by parasites, lamellocytes rapidly differentiated (Labrosse et al., 2005). However, in mutant hop ${ }^{\text {Tum-1 with }}$ enriched lamellocytes, PPO3 was expressed with accompanying spontaneous melanization (Luo et al., 1995; Nam et al., 2008). When DmPPO3 was overexpressed in various D. melanogaster tissues using a UAS-GAL4 system, the corresponding tissues were melanized (Nam et al., 2008), indicating that PPO3 can autoactivate independently of serine protease cleavage (Liu et al., 2012). The addition of $\mathrm{Cu}^{2+}$ or substrate L-DOPA to culture media resulted in auto-melanization of DmPPO3-expressing S2 cells, which was not due to serine protease cleavage (Nam et al., 2008; Liu et al., 2012).

Three D. melanogaster PPOs were modeled from the predicted MsPPO crystal structures (Chen et al., 2012), and the blocking residue was removed to expose the active site pocket of each PPO using Pymol. Compared to DmPPO1 and DmPPO2, DmPPO3 has a large active pocket, and thus some substrate may enter through the gap between the place holder and entrance. The model predicted that two important amino acids ( $\mathrm{I}^{218}$ in Copper $A$ and $\mathrm{A}^{393}$ in Copper B of DmPPO3) would affect the size of active site pocket. When these two amino acids were mutated to reduce the size of the active site pocket, the auto-activation property of DmPPO3 was restored (Chen et al., 2012). The corresponding amino acids in other insect PPOs are also variable (Chen et al., 2012).

DmPPO1 and DmPPO2 have a loop extending out of the protein at the C-terminus (Chen et al., 2012), but DmPPO3 has lost this fragment and has a short helix in its place. When the corresponding sequence from DmPPO1 was added to DmPPO3, the auto-activation of mutant DmPPO3 decreased significantly. Therefore, the missing fragment may also influence DmPPO3 auto-activation. Deletion of the corresponding sequence affects the activity of DmPPO2 but not of DmPPO1 after a activation by ethanol. Notably, the sequence corresponding to the extending loop lost a variable number of amino acids in most mosquito PPOs (Chen et al., 2012). Elucidating the sequences of amino 
acids that can affect DmPPO3 activity is challenging if we have no MsPPO crystal structure for reference.

In M. sexta, the tight heterodimer structure of MsPPO1 and MsPPO2 is formed through extensive hydrophobic and chargecharge interaction ( $\mathrm{Li}$ et al., 2009). This suggests that it may be possible to tag another protein at the C-terminus of insect PPO. The fused protein DmPPO-GFP was expressed in S2 cells and E. coli with green fluorescence and $\mathrm{PO}$ activity, and they were also activated by ethanol and serine protease separately (Yang et al., 2013). In future, in vivo expression of PPO-GFP would facilitate investigation of its functions in cellular and humoral immunity.

Most insect PPOs and arthropod hemocyanin have two disulfide bonds at the C-terminus. However, each PPO in the parasitic wasp Pimpla hypochondriaca has only one disulfide bond (Parkinson et al., 2001). Protein folding and stability can be improved by disulfide bond formation (Sevier and Kaiser, 2002). Deletion of one or both disulfide bonds in DmPPO1 did not cause DmPPO1 to break down (Lu et al., 2014b), but the activities of DmPPO1 expressed in S2 cells and E. coli decreased significantly. Deletion of disulfide bonds also reduced thermostability of DmPPO1. Furthermore, the antibacterial activity of DmPPO1 in which one or both of the disulfide bonds had been deleted was decreased (Lu et al., 2014b). Since type-3 copper proteins exist in almost all organisms (Aguilera et al., 2013), this group of proteins may be suitable markers for the study of evolution. The identification of important amino acids and fragments in insect PPO and other type- 3 copper proteins may aid the understanding of when, why, and how type-3 copper proteins adapt to different environments and evolve to serve different physiological functions.

\section{PPO ACTIVATION}

Melanization catalyzed by active phenoloxidase (PO) ( $\mathrm{PO}$ is cleaved into $\mathrm{PO}$ by serine proteases) in insects is central to sequestering invading pathogens and healing wounds (Ashida and Brey, 1997; Lai et al., 2002; Kanost and Gorman, 2008; Nam et al., 2012). In insect hemolymph, PO exists as PPO zymogen that must be activated by proteolytic cleavage (Ashida and Brey, 1997; Cerenius et al., 2008; Kanost and Gorman, 2008). A serine proteinase cascade for insect PPO activation was proposed in 1986 (Yoshida and Ashida, 1986). Subsequently, many proteins—such as PPO-activating enzyme (PPAE) (Ashida and Brey, 1995, 1997), PPO-activating proteinases (PAPs) (Jiang et al., 2003a,b, 2011), D. melanogaster protease MP1, MP2, and Hayan (Tang, 2009; Nam et al., 2012; An et al., 2013), serine proteinase homologs (SPHs) (Ross et al., 2003; Yu et al., 2003), PPO-activating factor (PPAF) (Lee et al., 1998), serpins (Michel et al., 2005; Bruning et al., 2007; Scherfer et al., 2008; Jiang et al., 2009; Zou et al., 2010), C-type lectins (Yu et al., 1999), $\beta$-1,3-glucan recognition proteins ( $\beta$ GRP) (Yu et al., 2002; Lee et al., 2004), Gramnegative bacteria-binding proteins (GNBP), and peptidoglycan recognition proteins (PGRP) (Takehana et al., 2002)—have been found to positively or negatively regulate PPO activation using B. mori, M. sexta, D. melanogaster, Holotrichia diomphalia, and mosquitoes as models. A detailed pathway for PPO activation in M. sexta was put forward following a number of biochemical studies (Jiang et al., 2003a,b; Yu et al., 2003; Zou and Jiang, 2005;
Kanost and Gorman, 2008). Briefly, in response to microorganism infection, hemolymph pattern-recognition proteins (PGRP, BGRP, and C-type lectin) bind to the microorganism's surface polysaccharides, inducing initiator protease(s) activation. Next, the initiator protease triggers a protease cascade, activating terminal serine proteases such as PPAE, PAP, or PPAF to cleave PPO and form active PO (Cerenius et al., 2008; Kanost and Gorman, 2008). Other proteases are likely involved in the process. For example, various serpins can limit the activity of corresponding proteinases, thereby limiting the reaction speed and avoiding excessive melanization in vivo (Kanost, 1999; Kanost et al., 2004). However, the literatures indicate that there are differences in the final step of PPO cleavage to produce activated PO in different species of insects. Three mechanisms are summarized as below (Figure 1).

\section{MECHANISM 1}

In B. mori, PPAE purified from cuticles directly cleaved BmPPO into active PO (Ashida and Brey, 1997). The N-terminus amino acid sequences of POs showed that B. mori PPO1 $(78.78 \mathrm{kD})$ and PPO2 $(80.12 \mathrm{kD})$ were both cleaved at ${ }^{51} \mathrm{RF}^{52}$, and large fragments (BmPO1, $72.82 \mathrm{kD}$; BmPO2, 74.25 kD) had direct $\mathrm{PO}$ activity (Figure 1A) (Yasuhara et al., 1995; Ashida and Brey, 1997). In the BmPPO activation cascade, PGRP and BGRP detect invading microorganisms, and PPAE is subsequently cleaved and activated (Ashida et al., 1983; Ashida and Brey, 1997). BAEE and $\mathrm{Ca}^{2+}$ are involved in this pathway, but BAEE does not directly activate PPAE (Yoshida and Ashida, 1986; Ashida and Brey, 1997). Recently, several proteins that function in silkworm nodule melanization have been identified (Sakamoto et al., 2011; Chen et al., 2014; Tokura et al., 2014), most of which are similar to the MsPPO activation pathway. The PPO activation pathway in B. mori will likely be clarified in the future.

\section{MECHANISM 2}

In M. sexta, MsPPO is activated via a more complicated mechanism than in $B$. mori, and biochemical studies have identified many proteins that regulate PPO activation (Jiang et al., 2003a,b; Yu et al., 2003; Zou and Jiang, 2005; Zou et al., 2005). PPO activation in $M$. sexta is also initiated when the corresponding pattern-recognition receptors bind to elicitors on invading microorganisms, which is similar in most insects. Three PAPs are known to cleave PPO directly at the same conserved sequence $\left({ }^{51} \mathrm{RF}^{52}\right.$ in MsPPO1; ${ }^{49} \mathrm{RV}^{50}$ in MsPPO2) where PPAE cleaved BmPPO (Ashida and Brey, 1997; Jiang et al., 2003a,b). However, the large cleaved fragments (MsPO1, $72.86 \mathrm{kD}$; MsPO2, $74.14 \mathrm{kD}$ ) have very low PO activity. When SPHs were added, PO activity increased significantly (Yu et al., 2003) (Figure 1B). M. sexta SPH-1 and SPH-2 associate loosely with PAP1 (or PAP3) and PPO to form a large complex (Wang and Jiang, 2004; Gupta et al., 2005). Based on the crystal structure of MsPPO2 and the computer-modeled structures of activated MsPO2, the surface electrostatic charge is changed from largely negative to mainly positive when the $\mathrm{N}$-terminal sequence is cleaved at $\mathrm{R}^{51}$ ( $\mathrm{Li}$ et al., 2009). PAP-2 has three positively charged areas in its dual-clip domains (Huang et al., 2007), one of which may first associate with $\mathrm{MsPPO}$ in the negatively charged region. When the 


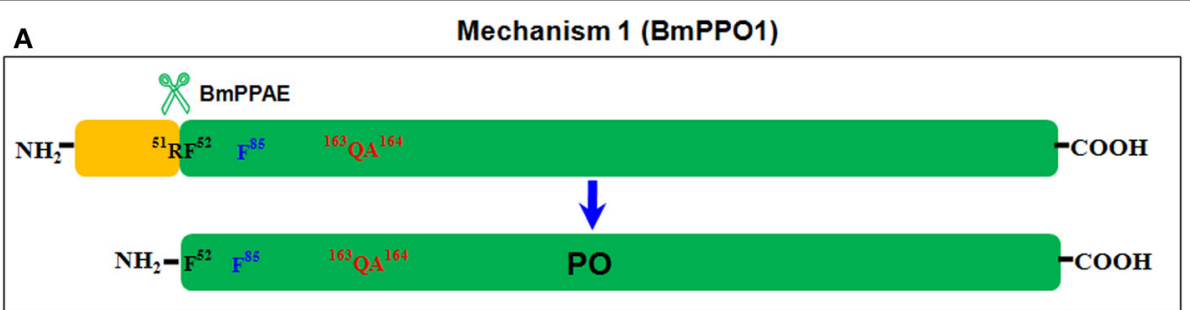

B

Mechanism 2 (MsPPO1)
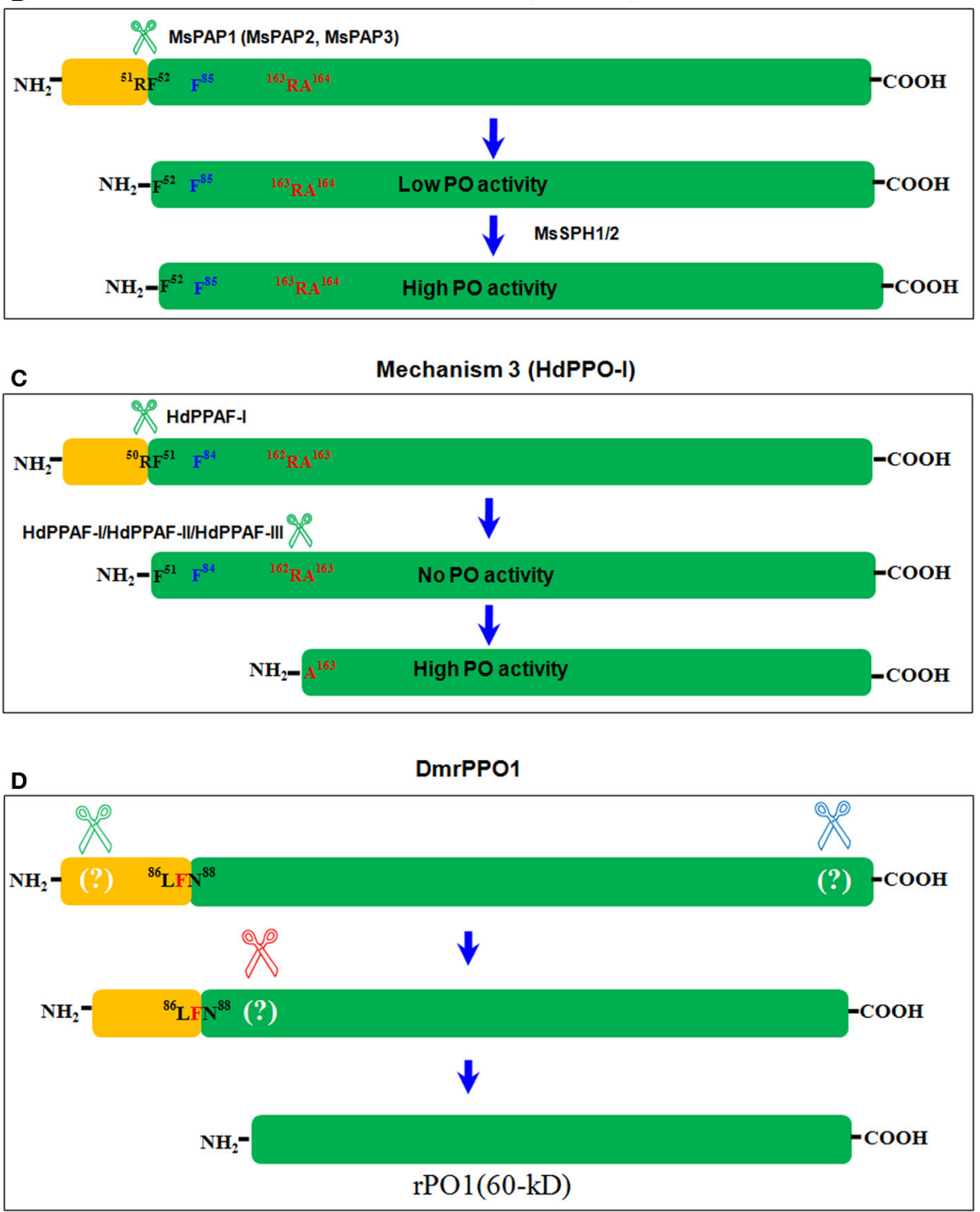

FIGURE 1 | Three mechanisms of insect PPO activation. The terminal serine protease cleaves PPO differently among insect species (Ashida and Brey, 1997; Lee et al., 1998; Kim et al., 2002; Kanost and Gorman, 2008). And the three mechanisms diverge based on these differences. Here, we consider only BmPPO1 (Accession: NP_001037335), MsPPO1 (Accession: 044249), and HdPPO1 (Accession: BAC15603) as a summary. The conserved bonds ${ }^{51} \mathrm{RF}^{52}$ in BmPPO1 (A), ${ }^{51} \mathrm{RF}^{52}$ in MsPPO1 (B), and ${ }^{50} \mathrm{RF}^{51}$ in HdPPO1 (C) were cleaved by serine proteases separately in the same way, as shown. $\mathrm{F}^{85}$ in $\mathrm{BmPPO} 1, \mathrm{~F}^{85}$ in MsPPO1, and $\mathrm{F}^{84} \mathrm{HdPPO} 1$ (labeled in blue) function as the place holder in the respective active site pockets, and may block substrates until they are dislodged. In HdPPO1, ${ }^{162}$ RA $^{163}$ was further cleaved to form a fragment at $60 \mathrm{kD}$ with PO activity (C). The corresponding sequences in BmPPO1 (A) and
MsPPO1 (B) are also shown in red. In B. mori, BmPPO was cleaved by PPAE to produce PO (Ashida and Brey, 1997) (A). In M. sexta, PAPs cleaved MsPPO in the same place as in $B$. mori to produce $P O$ fragments with low enzyme activity. When SPHs were added, PO activity increased significantly (Kanost and Gorman, 2008) (B). In H. diomphalia, HdPPO was cleaved as in BmPPO and MsPPO by PPAF-I at the conserved bond ${ }^{50} \mathrm{RF}^{51}$. However, the large fragment had no PO activity unless PPAF-I, PPAF-II, and PPAF-III were combined, and was cleaved again at ${ }^{162} \mathrm{RA}^{163}$ to produce a fragment at $60 \mathrm{kD}$; this fragment had $\mathrm{PO}$ activity (Lee et al., 1998; Kim et al., 2002) (C). In an in vitro assay, commercial $\alpha$-chymotrypsin cleaved D. melanogaster recombinant PPO1 (Accession: AAF57775) (rPPO1) in at least three places to produce a fragment, also of $\sim 60$ kD, with direct enzyme activity (Lu et al., 2014a) (D). 
$\mathrm{N}$-terminal sequence is cleaved by PAP, the exposed positively charged region is ready for the $\mathrm{SPH}$ association since, according to a study in $H$. diomphalia (Piao et al., 2005), SPH has a negatively charged surface in the clip domain. The association of SPHs with activated $\mathrm{MsPO}$ may induce $\mathrm{MsPO}$ domain I into conformational changes, dislodging the place holder from the active site pocket and allowing substrates to enter (Li et al., 2009). In M. sexta, hemolymph proteinases HP14 and HP21 are involved in the MsPPO activation cascade (Ji et al., 2004; Wang and Jiang, 2006; Gorman et al., 2007). Active HP14 cleaves ProHP21 to produce active HP21, which then cleaves ProPAPs to produce active PAPs (Kanost et al., 2004; Kanost and Gorman, 2008). Serpin-3, serpin-4, serpin-6, and serpin-1J negatively regulate each step of the cascade (Kanost et al., 2004; Kanost and Gorman, 2008).

\section{MECHANISM 3}

The PPO activation pathway of $H$. diomphalia has also been determined. In $H$. diomphalia, three PPO-activating factor (PPAF-I, PPAF-II, and PPAF-III) have been identified (Lee et al., 1998; Kim et al., 2002). PPAF-II is similar to M. sexta SPH and contains a non-catalytic clip domain (Lee et al., 1998; Kim et al., 2002). As with B. mori PPAE and M. sexta PAPs, PPAF-I cleaves HdPPO-I at the conserved Arg-Phe $\left({ }^{50} \mathrm{RF}^{51}\right)$ bond, and the large fragment $(76 \mathrm{kD})$ is inactive (Lee et al., 1998; Kim et al., 2002). However, when all PPAFs were mixed with purified HdPPO-I in a buffer containing $\mathrm{Ca}^{2+}$, a new fragment $(60 \mathrm{kD})$ with $\mathrm{PO}$ activity was produced in addition to the 76-kD fragment (Lee et al., 1998; Kim et al., 2002). N-terminal sequencing shows that the $60-\mathrm{kD}$ fragment was cleaved between ${ }^{162} \mathrm{RA}^{163}$ in HdproPO-I. Therefore, in $H$. diomphalia, HdPPO is not activated until it is cleaved at two regions (Figure 1C). Based on the MsPPO crystal structure, the second cleavage occurs after the place holder, and exposes the active site pocket (Li et al., 2009).

$\alpha$-chymotrypsin is a typical serine protease and, when used to cleave BmPPO, resulted in PO activity (Ohnishi et al., 1970). Galleria mellonella PPO (GmPPO) was also mixed with $\alpha$-chymotrypsin but no PO activity was even indicated (Kopácek et al., 1995). Another study mixed purified recombinant DmPPO1 with trypsin and $\alpha$-chymotrypsin separately, and found that $\alpha$-chymotrypsin cleaved DmPPO1 into two bands after separation on a native gel: one $(\sim 60 \mathrm{kD})$ with direct PO activity, and the other $(\sim 76 \mathrm{kD})$ that requires activation by ethanol ( $\mathrm{Lu}$ et al., 2014a). When His-tag was added to DmPPO1 at either the $\mathrm{N}$ - or C-terminus and evaluated using antibodies against His-tag, no signals were detected with the two bands. This indicates that $\alpha$-chymotrypsin initially cleaves DmPPO1 at both the $\mathrm{N}$ - and Cterminus simultaneously. The $76-\mathrm{kD}$ band requiring ethanol activation was produced rapidly, with a mass ratio of DmPPO1 and $\alpha$-chymotrypsin at 70:1, and DmPPO1 disappeared within the assayed time. Next, the mass ratio of DmPPO1 to $\alpha$-chymotrypsin was changed to $1: 1$, and the $76-\mathrm{kD}$ band was further cleaved after the place holder to produce a $60-\mathrm{kD}$ fragment with direct PO activity. Thus, $\alpha$-chymotrypsin cleaved DmPPO1 in at least three places, producing active $\operatorname{DmPO} 1(60 \mathrm{kD})$ : first at the $\mathrm{N}$ and C-termini simultaneously to produce DmPPO1(76 kD), and second after the place holder to form DmPO1 $(60 \mathrm{kD})$ ( $\mathrm{Lu}$ et al., 2014a), as summarized in Figure 1D. In this work, the 3D view of different potential cleaving sites were also compared in a supplementary picture ( $\mathrm{Lu}$ et al., 2014a), which may be helpful to understand the cleavage and activation. In Aedes aegypti, two immune melanization proteases (IMP-1 and IMP-2) induce melanization against parasites, cleaving Arg or Lys around the 162-position and producing active AaPO (50 kD) (Zou et al., 2010). In A. aegypti, a purified fragment with a molecular weight of $60 \mathrm{kD}$ had PO activity upon activation using detergents or 2-propanol. According to a LC-MS/MS assay, this fragment contained PPO1, PPO2, and PPO3 fragments (Li et al., 2005). This might be due to mRNA splicing among the three PPOs. Activation of DmPPO1 by $\alpha$-chymotrypsin indicates that it is possible for PPO to be directly cleaved for activation. However, further work will be necessary to determine whether there is a serine protease that functions similar commercial $\alpha$-chymotrypsin in insects, as the described work was performed in vitro (Lu et al., 2014a).

Trypsin is another typical serine protease. According to predictions using the GPMAW software (http://www.gpmaw.com/), trypsin can precisely cleave DmPPO1 at ${ }^{52} \mathrm{RF}^{53}$ and ${ }^{16} \mathrm{RD}^{165}$ (Lu et al., 2014a), which correspond to ${ }^{51} \mathrm{RF}^{52}$ in BmPPO1 and ${ }^{162}$ RA $^{163}$ in HdPPO-I (Ashida and Brey, 1997; Lee et al., 1998; Kim et al., 2002). Therefore, in prediction, trypsin should cleave DmPPO1 to produce DmPO1 with a molecular weight of either $76 \mathrm{kD}$ (as in B. mori and M. sexta) or $60 \mathrm{kD}$ (as in H. diomphalia). Results showed that trypsin cleaved DmPPO1 into a $60-\mathrm{kD}$ fragment that could be further activated by ethanol but not by $\alpha$-chymotrypsin ( $\mathrm{Lu}$ et al., 2014a). Therefore, the protein structure of insect PPO likely affects its activation by serine protease cleavage. Based on their crystal structures, MsPPO1 and MsPPO2 differ in their surface electric charge and structure (Figure 2), which may complicate PPO activation since the electrostatic interactions of MsPPO, SPH, and PAPs are involved in the activation process ( $\mathrm{Li}$ et al., 2009). In addition to serine protease, detergents such as sodium dodecyl sulfate (SDS), CPC, and ethanol can activate insect PPO (Asada et al., 1993; Ashida and Brey, 1997). Cationic detergents are thought to interact with PPO through electrostatic interaction, causing conformational changes and dislodging the place holder (Li et al., 2009). Since it is easy to obtain large amounts of recombinant PPO by expression in E. coli, the mechanism of ethanol activation will likely be elucidated by means of determination of crystal structures.

DmPPO3 is a unique PPO in D. melanogaster, since it displays the direct $\mathrm{PO}$ activity that cannot be explained by the mechanisms described above (Nam et al., 2008; Liu et al., 2012). PPO released into the hindgut of $B$. mori directly induces feces melanization (Shao et al., 2012), but it is unclear how BmPPO is activated in the hindgut. Some proteinases have been identified in larval hindgut contents (Shao et al., 2012); these may be involved in PPO activation in the hindgut.

In a word, PPO activation in insects is much more complicated than we understood. Many more serine proteases are probably involved in PPO cleavage and activations in one of mechanisms as described above. With the genome of many insects available, it is the time to do a screening to see how many serine proteases or even other proteases that can cleave insect PPO for activation. 


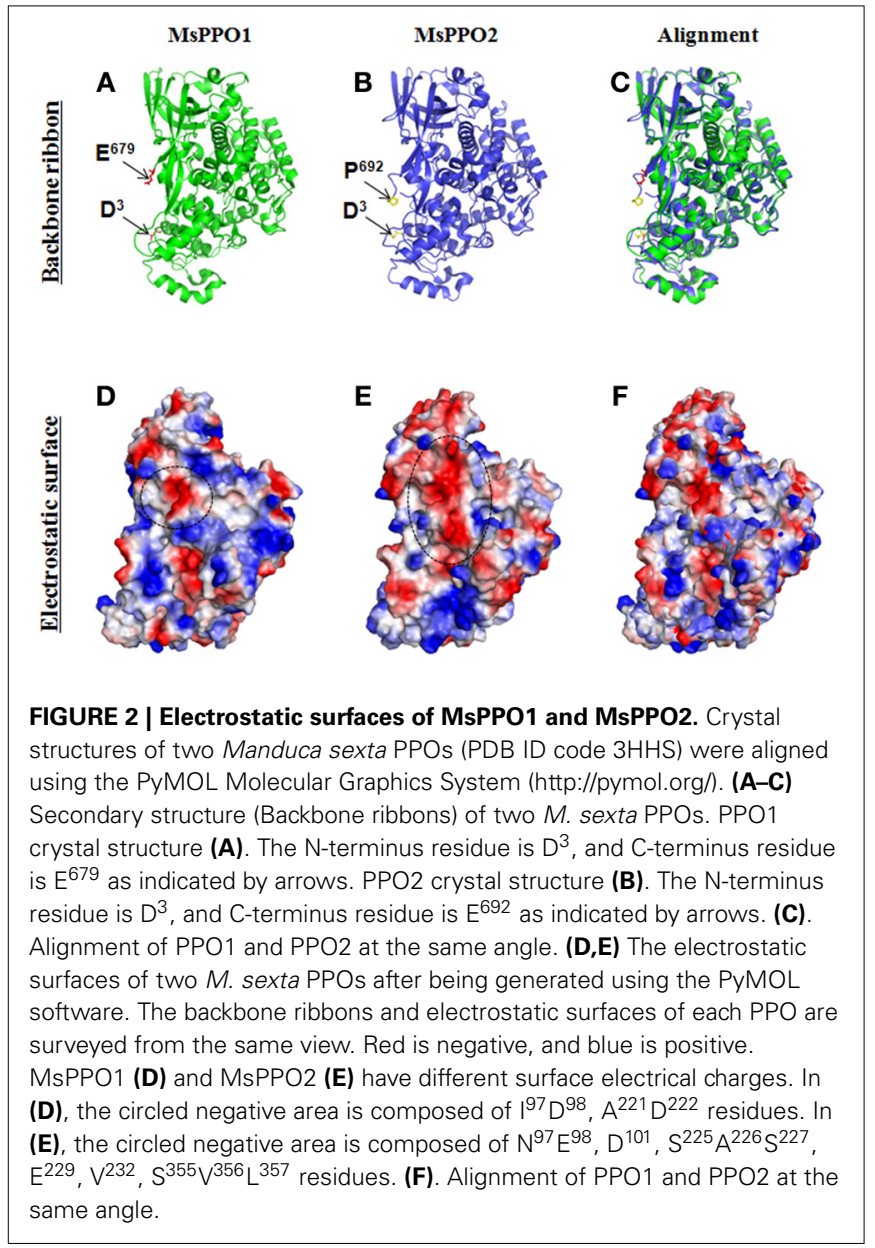

PROPERTIES OF ACTIVE PO AND ITS NEGATIVE REGULATION $\alpha$-chymotrypsin cleaves recombinant DmPPO1 into a fragment known as DmPO1 $(60 \mathrm{kD})$, which has direct PO activity (Lu et al., 2014a). Apo-DmPPO1 can be purified without the addition of $\mathrm{Cu}^{2+}$ in the culture medium. Active PO is easily adsorbed on the surfaces of many materials and forms aggregates with itself and other molecules (Ashida and Brey, 1997). When used for PPO activation, apo-DmPPO1 can overcome the associated properties of $\mathrm{PO}$, resulting in the production of active DmPO1 $(60 \mathrm{kD})$ upon addition of $\mathrm{Cu}^{2+}$. DmPO1 $(60 \mathrm{kD})$ was lost on the native gel after incubation with dopamine, likely because it formed large molecules with dopamine, as suggested by SDS-PAGE (Lu et al., 2014a). DmPO1(60 kD) activity was not affected by high temperature $\left(37^{\circ} \mathrm{C}\right)$ or $\mathrm{NaCl}$ (high concentrations), and staining of a native gel showed that EDTA did not chelate $\mathrm{Cu}^{2+}$ in the active site pocket. Notably, DmPO1 $(60 \mathrm{kD})$ separated on a native gel associates into a $\sim 260 \mathrm{kD}$ molecule upon resolution by denaturing SDS-PAGE (Lu et al., 2014a). In B. mori, the wound activated PO oxidizes Tyr residues in other proteins to produce o-quinones that can be covalently cross-linked with $\mathrm{PO}$ and several other proteins to form large complex ( $\sim 670 \mathrm{kD})$ (Clark and Strand, 2013). This complex can use endogenous Tyr for rapid melanization.

During the melanization process, many toxic molecules—such as cytotoxic quinones and reactive oxygen-are produced
(Christensen et al., 2005; Nappi and Christensen, 2005). In most cases, melanization is limited to invading microorganisms. Uncontrolled and systematic melanization is also lethal to insects and, therefore, insects have many means of regulating melanization. Serpins regulate the time and locations of melanization by inhibiting the corresponding protease activity, which occurs before the PO formation (Kanost and Gorman, 2008). Additionally, several small peptides or large proteins have been shown to regulate $\mathrm{PO}$ activity, as does a $4-\mathrm{kD}$ hemolymph peptide from Musca domestica, Anophele gambiae, and M. sexta (Tsukamoto et al., 1992; Sugumaran and Nellaiappan, 2000; Lu et al., 2008). A 380-kD PO inhibitor from M. sexta larval cuticles, and a 43-kD melanization inhibitor from Tenebrio melitor, also inhibit PO activity, thus avoiding systematic melanization in the hemolymph (Sugumaran and Nellaiappan, 2000; Zhao et al., 2005). However, the exact mechanisms by which these proteins inhibit $\mathrm{PO}$ activity are unclear.

In A. aegypti, CLSP2 containing C-type lectin (CTL) and elastase-like SP domains reduced hemolymph melanization. When $A$. aegypti adults underwent acute infection, CLSP2 reduced hemolymph melanization (Shin et al., 2011). In CLSP2, the CTL domain is thought to function in pathogen detection, and the ESP domain is likely involved in regulating melanization. Plasmodium gallinaceum infection up-regulated CLSP2 gene transcription, and an RNAi assay showed that CLSP2 was required for parasite development. Thus, CLSP2 reduces PPO activation in response to parasite infection, which is advantageous to parasite development.

Lysozyme can also regulate PO-induced melanization. In $A$. gambiae, the binding of lysozyme C-1 inhibited Sephadex bead melanization (Li and Paskewitz, 2006). M. sexta lysozyme interacts with plasma PPO directly (Rao et al., 2010). Incubating naïve plasma with lysozyme inhibited the conversion of $\mathrm{MsPPO}$ to PO. However, PAP1 and SPH2, two important components of the MsPPO activation pathway, were degraded. This tradeoff between lysozyme and PO activity was also observed in Spodoptera littoralis larvae (Cotter et al., 2008), wherein dark lines had higher lysozyme activity but PO activity was decreased, and pale lines had lower lysozyme but higher PO activity. Therefore, lysozyme is another negative regulator of $\mathrm{PPO}$ activation, which probably functions via interaction with PPO.

Several proteins and small molecules produced by insect pathogens have been found to regulate $\mathrm{PO}$ activity and melanization. Microplitis demoliter bracovirus (MdBV) produces a protein known as Egf 1.0 that has the same cleavage sequence, ArgPhe, as insect PPO for activation (Ashida and Brey, 1997; Beck and Strand, 2007). Egf 1.0 binds to M. sexta PAPs through its C-terminal repeat domain, and it can prevent pro-PAP and pro-SPH from activating PPO (Beck and Strand, 2007; Lu et al., 2008). The insect pathogen Metarhizium robertsii produces 39 cyclohexadepsi-peptide destruxins (dtxs) that can suppress both the cellular and humoral immune responses, especially hemolymph melanization (Wang et al., 2012). When either Dtx S1 or Dtx S2 was deleted from M. robertsii that could not produce dtxs, hemolymph from the infected insects could become melanized as naïve larvae in the air. This indicates that dtxs inhibits hemolymph PPO activation. Photorhabdus 
luminescens is a Gram-negative bacterium, and produces a small molecular antibiotic, (E)-1,3-dihydroxy-2-(isopropyl)-5(2-phenylethenyl)benzene (ST), that can also inhibit M. sexta PO activity (Eleftherianos et al., 2007). PO inhibitors produced by insects help to avoid harmful systematic melanization. However, PO inhibitors produced by pathogens allow them to escape the immune responses of host insects.

\section{PPO FUNCTIONS BEYOND IMMUNITY}

Insect PPO is an important innate immunity protein protecting hosts from infection, since it is rapidly activated in vivo (Hillyer et al., 2003, 2004). Insect PPO is also important for wound healing (Binggeli et al., 2014). However, many studies have shown that insect PPO has some functions beyond immunity. A recent study shows that epidermal cells in the B. mori hindgut can produce $\mathrm{BmPPO}$ and release it into the hindgut contents (Shao et al., 2012). Hindgut BmPPO is the reason that phytophagous insects excrete black feces despite consuming green leaves. When PO activity in the hindgut was inhibited by phenylthiourea (PTU), insects excreted green feces. Furthermore, these green feces contained many more bacteria than did black feces. Therefore, insects use the hindgut PPO to exterminate potential pathogens in the feces through melanization, thereby protecting their food from pollution by feces transferred pathogens. Another recent study shows that melanization triggered by active Hayan in $D$. melanogaster can activate the c-Jun-N terminal kinase (JNK) in neuronal tissues (Nam et al., 2012). When the integuments of adult D. melanogaster were experimentally damaged, inactive Hayan was activated and hemolymph PPO was cleaved to produce PO. PO-induced melanization yielded reactive oxygen species (ROS) that activate the neuronal JNK pathway and protect against further injury. Thus, the hemolymph Hayan-PO cascade links wound and neuron responses via ROS produced by melanization (Nam et al., 2012). In crayfish, when proPO was cleaved by proPO-activating enzyme (ppA), the N-terminal portion separated from PO displayed antibacterial activity, accompanying the agglutination of bacteria and altering cell morphology (Jearaphunt et al., 2014). Furthermore, crayfish proPO can also be cleaved by caspase-1L to produce two $\mathrm{N}$-terminal portions, proPOcasp $1(43 \mathrm{kD})$ and proPOcasp $2(45 \mathrm{kD})$, that also exhibit antibacterial activity. This work links caspase-induced inflammation and melanization for the first time. Melanization induced by PO activation combats microbial infections. In D. melanogaster, CG3066 is an indirect protease involved in activation of PPO to induce melanization. CG3066 mutants that lack PO activity had variable resistance and tolerance to various pathogens (Ayres and Schneider, 2008), indicating that their immune responses were tuned by evolution. These results indicate that many biological phenomena in insects are closely related to PPO and/or melanization. However, the focus of research should not be an immunity alone in the future.

Insect PPO and PO-induced melanization may affect insect longevity. D. melanogaster mutants with DmPPO1 and/or DmPPO2 deleted display novel phenotypes (Binggeli et al., 2014). Double mutants $\left(\mathrm{DmPPO}^{\Delta}{ }^{\Delta}, \mathrm{DmPPO}^{\Delta}\right)$ had significantly shorter longevity (half-life $=24$ days) than did the wild type, or $\mathrm{DmPPO}^{\Delta}{ }^{\Delta}$ and $\mathrm{DmPPO}{ }^{\Delta}$ single mutants. $\mathrm{DmPPO}^{\Delta}$ and $\mathrm{DmPPO}^{\Delta}$ single mutants were also shorter-lived than wild-type $D$. melanogaster. Identical results were observed under germ-free conditions. In $S$. littoralis, PO activity affects larval development time (Cotter et al., 2008). Pale lines have higher PO activity and take longer to develop into adults, while dark lines have lower PO activity but develop more rapidly. Yellow dung flies, Scathophaga stercoraria, were successfully selected to obtain separate lines with low and high PO activity (Schwarzenbach and Ward, 2006). Flies with high PO activity lived slightly longer than both the control and those with low PO activity. However, flies with high PO activity died earlier than others when starved. In A. gambiae, adult longevity was reduced when serpin-2 (SRPN2), but not its interactions, CLIPB9, was knocked down (An et al., 2011). SRPN-2 is a key component in negatively regulating melanization, and knock down of SRPN-2 induced melanotic pseudotumors in adults. Melanization induces the production of cytotoxic semiquinones and reactive oxygen intermediates, which likely contribute to reducing longevity (An et al., 2011). However, double knock-down of SRPN-2 and CLIPB9 rescues the phenotype induced by SRPN2 silencing (An et al., 2011). The interaction of SRPN-2 and CLIPB9 clearly influences adult longevity. Thus, insect PPO, including melanization induced by $\mathrm{PO}$, affects insect longevity.

The PPO may also affect insect development. B. mori larval wing discs and T. castaneum adult hind wings contain PPO proteins with unknown function (Diao et al., 2012; Dittmer et al., 2012). However, when prophenoloxidase III was knocked down in Armigeres subalbatus, the adult wings became abnormal (Tsao et al., 2009). Additionally, knock-down of A. subalbatus proPO III caused the incomplete formation of pupal endocuticles and pharate adult cuticles (Tsao et al., 2010), indicating that pro-PO III is a prerequisite for adult mosquito development. Furthermore, yellow dung flies with high PO activity had larger clutches and laid many more eggs than control insects, or those with low PO activity (Schwarzenbach and Ward, 2006). PPO was detected in B. mori silk glands using liquid chromatographytandem mass spectrometry (Dong et al., 2013); PPO and other proteins, such as laccase and peroxidase, appeared to cross-link the extracellular matrix. The tanning of the chorion of newly laid mosquito eggs occurs rapidly to avoid collapse, most likely due to evaporation under high summer temperatures. PPO was also detected in the mosquito eggshell (Li and Christensen, 1993; Marinotti et al., 2014). Chorion tanning is initiated by activating PO catalyzing L-tyrosine into L-DOPA ( $\mathrm{Li}$ and Christensen, 1993), after which L-DOPA decarboxylase (DDC) decarboxylates L-DOPA into dopamine. L-DOPA and dopamine are oxidized by $\mathrm{PO}$, tanning the egg chorion. When PO activity was inhibited, egg tanning was delayed. Therefore, PPO is also closely related to insect development.

Generally, when insects are infected by pathogens, their plasma PO activity will change (González-Santoyo and CórdobaAguilar, 2012). DNA microarray analysis of A. gambiae shows that AgPPO5, AgPPO6, and AgPPO9 are expressed rhythmically (Rund et al., 2011). Other proteins, such as several C-type lectins, clip-domain serine protease, and PGRP-that are involved in melanization are also expressed rhythmically, indicating that parasites in mosquito adults may adapt to the daily rhythm of host 
immunity (Rund et al., 2011). In A. aegypti, the expression of four PPO genes (AaPPO1, AaPPO3, AaPPO5, and AaPPO8) was activated by RUNT-related transcription factor 4 (RUNX4) upon microbial infection, under regulation by the Toll pathway (Zou et al., 2008). RUNX4 may also act cooperatively with REL1 to fight avian $P$. gallinaceum infection in adults.

There are up to 10 PPO genes in mosquitoes (Christophides et al., 2002; Waterhouse et al., 2007). It is unknown whether each PPO gene in mosquitoes and other insects has a novel function, and DmPPO was investigated with this in mind. In vitro (Asano and Takebuchi, 2009; Chen et al., 2012; Liu et al., 2012) and in vivo (Binggeli et al., 2014) studies have clarified many properties of each PPO in D. melanogaster. All three PPOs, including their corresponding PPO-GFP fused proteins, are expressed in E. coli or S2 cells with or without $\mathrm{Cu}^{2+}$ addition (Yang et al., 2013). DmPPO3 is unique since it can be auto-activated due to the presence of key amino acids and the loss of one fragment (Chen et al., 2012). DmPPO1 generally has higher PO activity than DmPPO2 when activated by ethanol or AMM1 (Li et al., 2012; Liu et al., 2012). DmPPO3 has the highest capacity for $\mathrm{Cu}^{2+}$ association, while that of DmPPO1 is intermediate and DmPPO2 associates with $\mathrm{Cu}^{2+}$ only at high concentrations. Separate deletions of DmPPO1 and DmPPO2 from $D$. melanogaster show that DmPPO1 exists mainly in the hemolymph, while DmPPO2 occurs within the crystal of crystal cells (Binggeli et al., 2014). DmPPO1 has antibacterial activity in vitro (Lu et al., 2014b). DmPPO1- and DmPPO2-deletion mutants show that DmPPO1 is more important than DmPPO2 in wound healing and defense against Gram-positive bacteria and fungi (Binggeli et al., 2014). Obviously, each insect PPO may have different properties. However, we neglect the study due to our attention on PPO activation change.

\section{MOLECULAR EVOLUTION OF INSECT PPO}

Insects are abundant animals, and each species of insect possesses at least one PPO gene. Mosquitos, for example, possess up to 10 PPO genes in the genome (Christophides et al., 2002; Waterhouse et al., 2007). Using "prophenoloxidase" as a keyword in a search of the National Center for Biotechnology Information (NCBI; http://www.ncbi.nlm.nih. gov/) database resulted in recovery of at least 75 insect PPO genes with full sequences deposited to date. A phylogenic tree for those insect PPOs was analyzed. The randomized axelerated maximum-likelihood (RAxML) method (The Exelixis Lab, Heidelberg, Germany) was used to reconstruct the phylogenetic relationships of insect PPOs based on amino acid sequences via the Cyberinfrasctructure for Phylogenetic Research (CIPRES) Science Gateway, with crustacean PPOs as the outgroup (Miller et al., 2010) (Figure 3). The phylogenetic structure indicates three major clades of insect PPO: Clade A comprises the conserved PPOs distributed among various insect orders, whereas Clades B and $C$ represent distinctive paralogs specifically occurring only in Lepidoptera and Diptera, respectively. In one unusual case, the Hemiptera PPO Choristoneura fumiferana PPO2 (ABW16862.1) was assigned to Clade $\mathrm{B}$. The origin and timing of the evolution of three separate PPO clades is unknown, and requires further study.
Arthropod PPO, hemocyanin, hexamerin, pseudohemocyanin, and hexamerin receptor amino acid sequences are similar (Burmester, 2002). These proteins serve different physiological functions, but all belong to the hemocyanin superfamily (Burmester, 2002) and contain $\sim 700$ amino acids each (Burmester, 2002). Insect PPO is an important innate immunity protein that is involved in cellular and humoral immune responses (Kanost et al., 2004; Cerenius et al., 2008; Kanost and Gorman, 2008). Following activation, PPO induces melanization around invading pathogens and wounds (Kanost et al., 2004; Cerenius et al., 2008; Kanost and Gorman, 2008). Hemocyanins are found in some arthropods and mollusks, and serve to transfer oxygen to tissues (van Holde and Miller, 1995; Kusche et al., 2002). The amino acid sequences of insect PPO and hemocyanin are highly conserved (Burmester, 2002). Each hemocyanin has two copper-binding sites, and each copper ion is coordinated by three histidines. Two copper ions in hemocyanin are a prerequisite for binding with oxygen (van Holde and Miller, 1995). Colorless hemocyanin turns blue after binding to oxygen (van Holde and Miller, 1995). Hemocyanin demonstrates PPO activity upon treatment with a detergent such as SDS (Decker et al., 2001). Hexamerin is widely accepted as a type of storage protein that primarily supplies nutrients during metamorphosis (Burmester and Scheller, 1999). Hexamerin is derived from hemocyanin (Burmester, 2002). Although it has no copper-binding sites, its amino acid sequence and protein structure are similar to those of PPO and hemocyanin (Willott et al., 1989). Hexamerin of the Coleoptera, Diptera, and Lepidoptera contains abundant aromatic amino acids, and is also known as arylphorin in these insect orders (Burmester and Scheller, 1999). Some Lepidoptera hexamerin also contains high amounts of methionine (Burmester, 2002).

The evolution of the type-3 copper protein has been analyzed elsewhere (Aguilera et al., 2013; Singh et al., 2013). Various types3 copper proteins have certain similarities among amino acid sequences. Type- 3 copper proteins are classified into $\alpha$ - (secreted form), $\beta$ - (cytosolic form), and $\gamma$-subclasses (membrane-bound form) (Aguilera et al., 2013). Insect PPO belongs to $\beta$ - subclasses. The $\alpha$-subclass appeared early, while the other two appeared later through gene duplication. So it is still unclear when and why insect PPO evolved to function as an immunity protein. Very interestingly, we also found that the amino acid sequences of Homo sapiens tyrosinase (Accession: AAB60319) and bacterial (Bacillus megaterium) tyrosinase (Accession: AAB60319) even exhibit around 30\% similarity (Figure 4). It is uncertain whether the tyrosinase of microorganisms and the tyrosinase of advanced animals share an evolutionary relationship, or if its occurrence in both groups is coincidental. As each type- 3 copper protein functions differently in different organisms, it is important to understand when and why these proteins evolved to fulfill their various physiological functions.

\section{FUTURE PROSPECTS}

In D. melanogaster, each PPO has unique properties and even functions. But the question remains: why do mosquitoes need so many PPO genes? Certainly, PPO and the melanization induced by activating $\mathrm{PO}$ are important factors in fighting malaria in vivo 


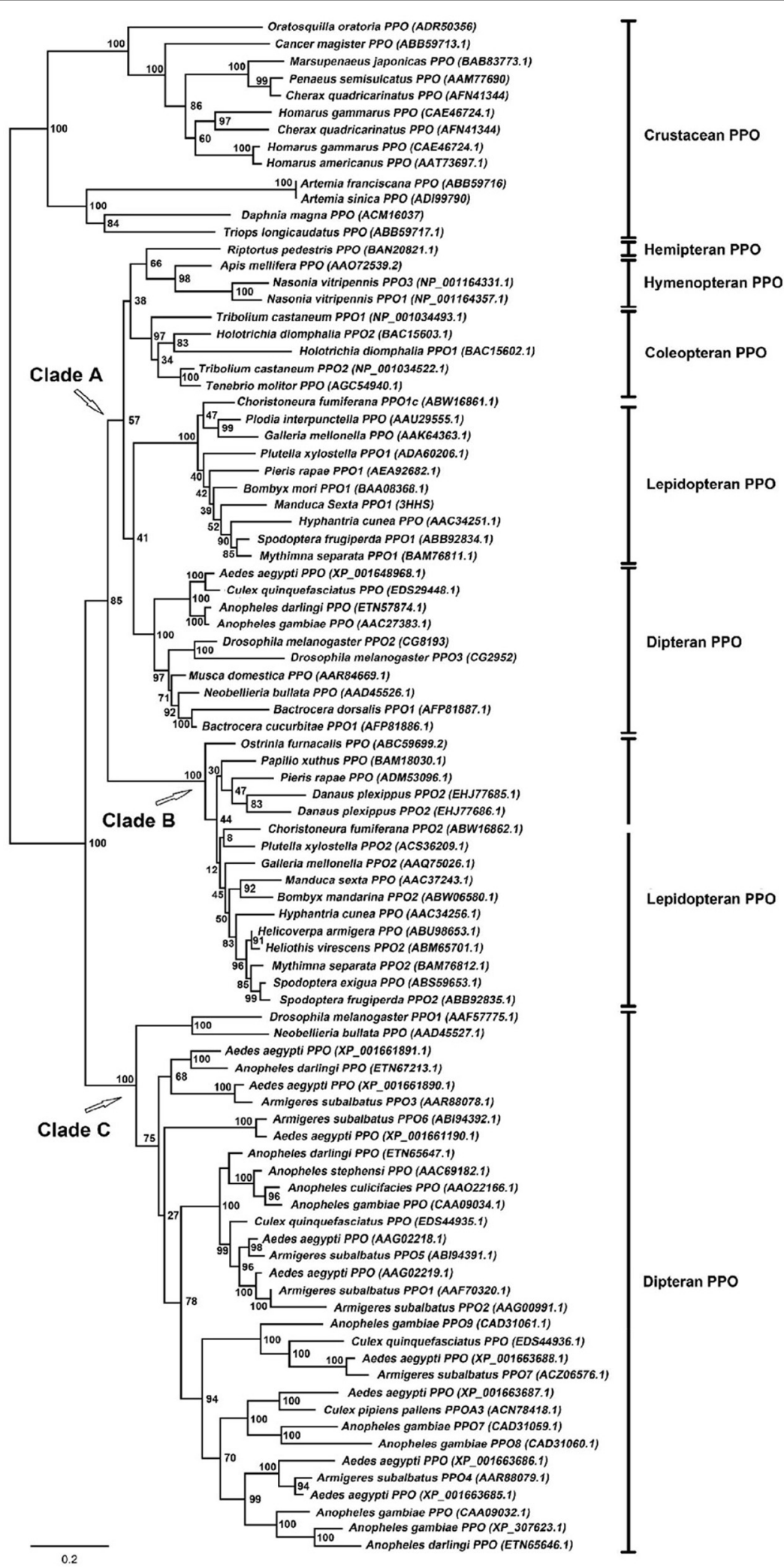

FIGURE 3 | Maximum-likelihood tree of insect prophenoloxidases calculated using the RAxML method via the CIPRES Science Gateway (Miller et al., 2010). Crustacean PPOs were used as an outgroup. The PPO genes from various insect species are indicated along with their NCBI accession numbers. 


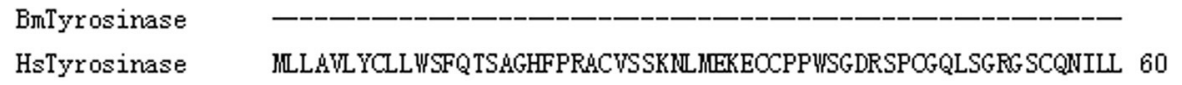

Bimtyrosinase

HsTyrosinase

Bimyrosinase

HsTyrosinase

BmTyrosinase

HsTyrosinase

HsTyrosinase

BmTyrosinase

HsTyrosinase

BuTyrosinase

HsTyrosinase

HsTyrosinase

BmTyrosinase

HsTyrosinase

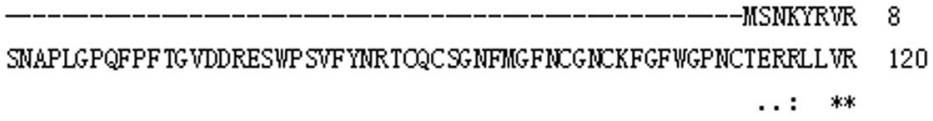

KNULH TDTEKRDVR-------------------TVLILKEKG TYDRYAAYH 42

FNIFDLSAPEKDKFFAYLTLAKHT ISSDYVIPIG TYGQMKNGSTPMFNDINTYDLFWNMH 180

$: *:: * * * * * *$,

:. : : : : .***: : :

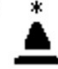

GAMGKHTPPGS--DDRNAMHNSSAFLPWHREYLLRFERDLQSIN—PEWTLPYWEWET 96

YNSMDALLGGSEIRD DFAHEAPAFLFWHRLFLLRWEQE IQKL TGDENF TIPYWDWR- 239

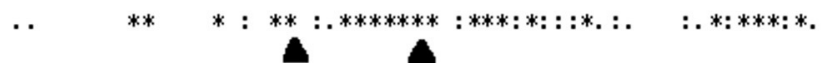

Copper A

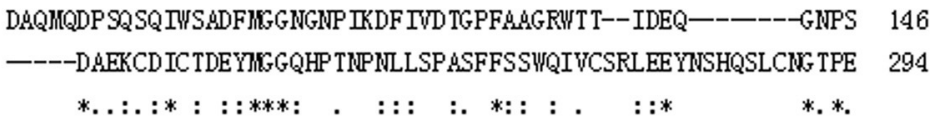

GGLKRNFG-ATEAP TLPTRDDVLNALKITQYDTPP WDMT SQNSFRNQLEGFIN--- 199 GPLRRNPGNHDKSRTPRLPSSADVEFCLSL TQYESG SMDKAMNF SFRNTLEGFASPL TGI 354

$* *: * * * \quad \ldots .: * * *: * * \quad . * .: * * *:: . *::: * * * * * * * *$.

---GPQLHINWHRWGGQMGWW TAPNDPVFFLHHANWDRWAWWIIHR-NQNYQPMK 254 ADASQSSMHALHIYMIGTMSQWQGSANDP IFLLHHAFVDSIFEQULQRHRPLQEWPEA 414

$\ldots: * *: *::: * *, * \quad: . * * *: *: * * * * * * * * \quad * \quad * * \quad *: \quad *$

$\Delta \mathbf{A}$

Copper B

WGPFGQN--FRDPMYPUNT TPEDWMRHRKLGYWDIELRKSKRSS-

297 NAPIGHNRESYNUPFIPLYRWGDFFISSKDLGYDYSYQDSDPDSFQDYIKSILEQASR

474
FIGURE 4 | Comparison of the amino acid sequences of Homo sapiens tyrosinase (HsTyrosinase; Accession number: AAB60319) and Bacillus megaterim tyrosinase (BmTyrosinase; Accession number: ACC86108). The online CLUSTALW multiple sequence alignment software (http://www. genome.jp/tools/clustalw/) was used for the slow and accurate pairwise alignment analysis. "*," Fully conserved residues; ":, conserved substitutions; ".," semi-conserved substitution as previously described (Grasela et al., 2008). Copper-binding regions A and B are underlined. The histidine residues marked with " $\mathbf{\Delta}$ " are the ligands proposed to coordinate two copper ions in the active site pocket.
(Collins et al., 1986). However, it is unclear if they have novel functions such as those described for A. subalbatus prophenoloxidase III (Tsao et al., 2009, 2010). It is likely that the various insect PPOs serve as-yet-unknown functions. As a typical copper 3 protein, insect PPO has been investigated for a long time (Ashida and Brey, 1997). Through outstanding research on PPO in B. mori, M. sexta, H. diomphalia, D. melanogaster, mosquitoes, and other invertebrates, it is clear that insect PPO is a critical factor in the defense against invading pathogens due to its rapid activation (Hillyer et al., 2003, 2004; Cerenius et al., 2008; Kanost and Gorman, 2008). Much is now understood about the PPO activation cascade in hemolymph (Kanost and Gorman, 2008). D. melanogaster has been used for investigation of the PPO activation pathway, and many important proteins that regulate PPO activation have been identified. The MP1, MP2, Hayan, and CG9737 proteases can cleave DmPPO (Tang, 2009; Nam et al., 2012; An et al., 2013). D. melanogaster serpins, such as Spn27A and Spn28D, negatively regulate PPO activation and melanization 
(Christensen et al., 2005; Nappi et al., 2005; Scherfer et al., 2008), while MP2 and Spn27A act together to regulate PPO activation (An et al., 2013). However, much about D. melanogaster PPO activation remains unclear. Some researchers will likely take advantage of $D$. melanogaster genetics and biochemistry to clarify the PPO activation pathway in $D$. melanogaster.

In B. mori, RNAi and recombinant Reeler injection recently showed that an immunity-induced Reeler is involved in the PPO activation pathway (Bao et al., 2008). Other novel proteins may be also involved in insect PPO activation, but this requires more research. In $M$. sexta, 163 conserved and 13 novel microRNAs have been identified, some of which may regulate the expression of genes in the PPO activation pathway (Zhang et al., 2014). Thus, the influence of microRNAs on insect PPO activation is an interesting subject for future research. Immune capacity and even longevity were seriously affected by knockdown and knock-out (deletion) of insect PPO (Binggeli et al., 2014), which indicates that insect PPO is an important factors for immunity protection. In contrast, pathogens secrete various small molecules to inhibit PO activity (Eleftherianos et al., 2007; Wang et al., 2012), which is advantageous for pathogens to escape host immunity. In future, it may be possible to apply these principles to pest control or production of beneficial insects and other invertebrates.

\section{ACKNOWLEDGMENTS}

This work was supported by the National Natural Science Foundation of China (31172151). We are grateful to Zhi-Qiang Lu for valuable discussion.

\section{REFERENCES}

Aguilera, F., McDougall, C., and Degnan, B. M. (2013). Origin, evolution and classification of type-3 copper proteins: lineage-specific gene expansions and losses across the Metazoa. BMC Evol. Biol. 13:96. doi: 10.1186/14712148-13-96

An, C., Budd, A., Kanost, M. R., and Michel, K. (2011). Characterization of a regulatory unit that controls melanization and affects longevity of mosquitoes. Cell. Mol. Life Sci. 68, 1929-1939. doi: 10.1007/s00018-010-0543-Z

An, C., Zhang, M., Chu, Y., and Zhao, Z. (2013). Serine protease MP2 activates prophenoloxidase in the melanization immune response of Drosophila melanogaster. PLoS ONE 8:e79533. doi: 10.1371/journal.pone.0079533

Aquino-Bolaños, E. N., and Mercado-Silva, E. (2004). Effects of polyphenol oxidase and peroxidase activity, phenolics and lignin content on the browning of cut jicama. Postharvest Biol. Tech. 33, 275-283. doi: 10.1016/j.postharvbio. 2004. 03.009

Asada, N., Fukumitsu, T., Fujimoto, K., and Masuda, K. (1993). Activation of prophenoloxidase with 2-propanol and other organic compounds in Drosophila melanogaster. Insect Biochem. Mol. Biol. 23, 515-520. doi: 10.1016/0965-1748 (93)90060-6

Asano, T., and Ashida, M. (2001). Cuticular pro-phenoloxidase of the silkworm, Bombyx mori. Purification and demonstration of its transport from hemolymph. J. Biol. Chem. 276, 11100-11112. doi: 10.1074/jbc.M0084 26200

Asano, T., and Takebuchi, K. (2009). Identification of the gene encoding prophenoloxidase A(3) in the fruitfly, Drosophila melanogaster. Insect Mol. Biol. 18, 223-232. doi: 10.1111/j.1365-2583.2008.00858.x

Ashida, M., and Brey, P. (1997). "Recent advances on the research of the insect prophenoloxidase cascade," in Molecular Mechanisms of Immune Responses in Insects, eds P. Brey and D. Hultmark (London: Chapman \& Hall), 135-172.

Ashida, M., and Brey, P. T. (1995). Role of the integument in insect defense: prophenol oxidase cascade in the cuticular matrix. Proc. Natl. Acad. Sci. U.S.A. 92, 10698-10702.
Ashida, M., Ishizaki, Y., and Iwahana, H. (1983). Activation of pro-phenoloxidase by bacterial cell walls or beta-1,3-glucans in plasma of the silkworm, Bombyx mori. Biochem. Biophys. Res. Commun. 113, 562-568.

Ayres, J. S., and Schneider, D. S. (2008). A signaling protease required for melanization in Drosophila affects resistance and tolerance of infections. PLoS Biol. 6:e305. doi: 10.1371/journal.pbio.0060305

Bao, Y. Y., Li, M. W., Zhao, Y. P., Ge, J. Q., Wang, C. S., Huang, Y. P., et al. (2008). Differentially expressed genes in resistant and susceptible Bombyx mori strains infected with a densonucleosis virus. Insect Biochem. Mol. Biol. 38, 853-861. doi: 10.1016/j.ibmb.2008.06.004

Beck, M. H., and Strand, M. R. (2007). A novel polydnavirus protein inhibits the insect prophenoloxidase activation pathway. Proc. Natl. Acad. Sci. U.S.A. 104, 19267-19272. doi: 10.1073/pnas.0708056104

Bidla, G., Dushay, M. S., and Theopold, U. (2007). Crystal cell rupture after injury in Drosophila requires the JNK pathway, small GTPases and the TNF homolog Eiger. J. Cell Sci. 120, 1209-1215. doi: 10.1242/jcs.03420

Biedermann, W., and Moritz, P. (1898). Beiträge zur vergleichenden Physiologie der Verdauung. Pflug. Arch. Eur. J. Phys. 73, 219-287.

Binggeli, O., Neyen, C., Poidevin, M., and Lemaitre, B. (2014). Prophenoloxidase activation is required for survival to microbial infections in Drosophila. PLoS Pathog. 10:e1004067. doi: 10.1371/journal.ppat.1004067

Bruning, M., Lummer, M., Bentele, C., Smolenaars, M. M., Rodenburg, K. W., and Ragg, H. (2007). The Spn4 gene from Drosophila melanogaster is a multipurpose defence tool directed against proteases from three different peptidase families. Biochem. J. 401, 325-331. doi: 10.1042/BJ20060648

Burmester, T. (2002). Origin and evolution of arthropod hemocyanins and related proteins. J. Comp. Physiol. B 172, 95-107. doi: 10.1007/s00360-001-0247-7

Burmester, T., and Scheller, K. (1999). Ligands and receptors: common theme in insect storage protein transport. Naturwissenschaften $86,468-474$.

Cerenius, L., Lee, B. L., and Soderhall, K. (2008). The proPO-system: pros and cons for its role in invertebrate immunity. Trends Immunol. 29, 263-271. doi: 10.1016/j.it.2008.02.009

Chen, K., Liu, C., He, Y., Jiang, H., and Lu, Z. (2014). A short-type peptidoglycan recognition protein from the silkworm: expression, characterization and involvement in the prophenoloxidase activation pathway. Dev. Comp. Immunol. 45, 1-9. doi: 10.1016/j.dci.2014.01.017

Chen, Y., Liu, F., Yang, B., Lu, A., Wang, S., Wang, J., et al. (2012). Specific amino acids affecting Drosophila melanogaster prophenoloxidase activity in vitro. Dev. Comp. Immunol. 38, 88-97. doi: 10.1016/j.dci.2012.04.007

Christensen, B. M., Li, J., Chen, C. C., and Nappi, A. J. (2005). Melanization immune responses in mosquito vectors. Trends Parasitol. 21, 192-199. doi: 10.1016/j.pt.2005.02.007

Christophides, G. K., Zdobnov, E., Barillas-Mury, C., Birney, E., Blandin, S., Blass, C., et al. (2002). Immunity-related genes and gene families in Anopheles gambiae. Science 298, 159-165. doi: 10.1126/science.1077136

Clark, K. D., and Strand, M. R. (2013). Hemolymph melanization in the silkmoth Bombyx mori involves formation of a high molecular mass complex that metabolizes tyrosine. J. Biol. Chem. 288, 14476-14487. doi: 10.1074/jbc.M113. 459222

Collins, F., Sakai, R., Vernick, K., Paskewitz, S., Seeley, D., Miller, L., et al. (1986). Genetic selection of a Plasmodium-refractory strain of the malaria vector Anopheles gambiae. Science 234, 607-610. doi: 10.1126/science.3532325

Cotter, S. C., Myatt, J. P., Benskin, C. M., and Wilson, K. (2008). Selection for cuticular melanism reveals immune function and life-history trade-offs in Spodoptera littoralis. J. Evol. Biol. 21, 1744-1754. doi: 10.1111/j.1420-9101.2008. 01587.x

Decker, H., Ryan, M., Jaenicke, E., and Terwilliger, N. (2001). SDS-induced phenoloxidase activity of hemocyanins from Limulus polyphemus, Eurypelma californicum, and Cancer magister. J. Biol. Chem. 276, 17796-17799. doi: 10.1074/ jbc.M010436200

Diao, Y., Lu, A., Yang, B., Hu, W., Peng, Q., Ling, Q. Z., et al. (2012). Existence of prophenoloxidase in wing discs: a source of plasma prophenoloxidase in the silkworm, Bombyx mori. PLoS ONE 7:e41416. doi: 10.1371/journal.pone. 0041416

Dittmer, N. T., Hiromasa, Y., Tomich, J. M., Lu, N., Beeman, R. W., Kramer, K. J., et al. (2012). Proteomic and transcriptomic analyses of rigid and membranous cuticles and epidermis from the elytra and hindwings of the red flour beetle, Tribolium castaneum. J. Proteome Res. 11, 269-278. doi: 10.1021/ pr2009803 
Dong, Z., Zhao, P., Wang, C., Zhang, Y., Chen, J., Wang, X., et al. (2013). Comparative proteomics reveal diverse functions and dynamic changes of Bombyx mori silk proteins spun from different development stages. J. Proteome Res. 12, 5213-5222. doi: 10.1021/pr4005772

Eleftherianos, I., Boundy, S., Joyce, S. A., Aslam, S., Marshall, J. W., Cox, R. J., et al. (2007). An antibiotic produced by an insect-pathogenic bacterium suppresses host defenses through phenoloxidase inhibition. Proc. Natl. Acad. Sci. U.S.A. 104, 2419-2424. doi: 10.1073/pnas.0610525104

Fu, Q., Li, P., Xu, Y., Zhang, S., Jia, L., Zha, X., et al. (2011). Proteomic analysis of larval integument, trachea and adult scale from the silkworm, Bombyx mori. Proteomics 11, 3761-3767. doi: 10.1002/pmic.201000506

Galko, M. J., and Krasnow, M. A. (2004). Cellular and genetic analysis of wound healing in Drosophila larvae. PLoS Biol. 2:e239. doi: 10.1371/journal.pbio.0020239

Gerdemann, C., Eicken, C., and Krebs, B. (2002). The crystal structure of catechol oxidase: new insight into the function of type-3 copper proteins. Acc. Chem. Res. 35, 183-191. doi: 10.1021/Ar990019a

González-Santoyo, I., and Córdoba-Aguilar, A. (2012). Phenoloxidase: a key component of the insect immune system. Entomol. Exp. Appl. 142, 1-16. doi: 10.1111/j.1570-7458.2011.01187.x

Gorman, M. J., Wang, Y., Jiang, H., and Kanost, M. R. (2007). Manduca sexta hemolymph proteinase 21 activates prophenoloxidase-activating proteinase 3 in an insect innate immune response proteinase cascade. J. Biol. Chem. 282, 11742-11749. doi: 10.1074/jbc.M611243200

Grasela, J. J., McIntosh, A. H., Shelby, K. S., and Long, S. (2008). Isolation and characterization of a baculovirus associated with the insect parasitoid wasp, Cotesia marginiventris, or its host, Trichoplusia ni. J. Insect Sci. 8, 1-19. doi: 10.1673/031.008.4201

Gupta, S., Wang, Y., and Jiang, H. (2005). Manduca sexta prophenoloxidase (proPO) activation requires proPO-activating proteinase (PAP) and serine proteinase homologs (SPHs) simultaneously. Insect Biochem. Mol. Biol. 35, 241-248. doi: 10.1016/j.ibmb.2004.12.003

Harbowy, M. E., and Balentine, D. A. (1997). Tea chemistry. Crit. Rev. Plant Sci. 16, 415-480. doi: 10.1080/713608154

Hillyer, J. F., Schmidt, S. L., and Christensen, B. M. (2003). Hemocyte-mediated phagocytosis and melanization in the mosquito Armigeres subalbatus following immune challenge by bacteria. Cell Tissue Res. 313, 117-127. doi: 10.1007/s00441-003-0744-y

Hillyer, J. F., Schmidt, S. L., and Christensen, B. M. (2004). The antibacterial innate immune response by the mosquito Aedes aegypti is mediated by hemocytes and independent of Gram type and pathogenicity. Microbes Infect. 6, 448-459. doi: 10.1016/j.micinf.2004.01.005

Huang, R., Lu, Z., Dai, H., Velde, D. V., Prakash, O., and Jiang, H. (2007). The solution structure of clip domains from Manduca sexta prophenoloxidase activating proteinase-2. Biochemistry 46, 11431-11439. doi: 10.1021/bi7010724

Iwama, R., and Ashida, M. (1986). Biosynthesis of prophenoloxidase in hemocytes of larval hemolymph of the silkworm, Bombyx mori. Insect Biochem. 16, 547. doi: 10.1016/0020-1790(86)90032-6

Jearaphunt, M., Noonin, C., Jiravanichpaisal, P., Nakamura, S., Tassanakajon, A., Soderhall, I., et al. (2014). Caspase-1-like regulation of the proPO-system and role of ppA and caspase-1-like cleaved peptides from proPO in innate immunity. PLoS Pathog. 10:e1004059. doi: 10.1371/journal.ppat.1004059

Ji, C., Wang, Y., Guo, X., Hartson, S., and Jiang, H. (2004). A pattern recognition serine proteinase triggers the prophenoloxidase activation cascade in the tobacco hornworm, Manduca sexta. J. Biol. Chem. 279, 34101-34106. doi: 10.1074/jbc.M404584200

Jiang, H., Vilcinskas, A., and Kanost, M. (2011). "Immunity in Lepidopteran insects," in Invertebrate Immunity, ed K. Söderhäll (New York, NY: Springer), 181-204.

Jiang, H., Wang, Y., Ma, C., and Kanost, M. R. (1997). Subunit composition of prophenol oxidase from Manduca sexta: molecular cloning of subunit ProPO-P1. Insect Biochem. Mol. Biol. 27, 835-850. doi: 10.1016/S0965-1748(97)00066-0

Jiang, H., Wang, Y., Yu, X. Q., and Kanost, M. R. (2003a). Prophenoloxidaseactivating proteinase-2 from hemolymph of Manduca sexta. A bacteriainducible serine proteinase containing two clip domains. J. Biol. Chem. 278, 3552-3561. doi: 10.1074/jbc.M205743200

Jiang, H., Wang, Y., Yu, X. Q., Zhu, Y., and Kanost, M. (2003b). Prophenoloxidaseactivating proteinase-3 (PAP-3) from Manduca sexta hemolymph: a clipdomain serine proteinase regulated by serpin-1J and serine proteinase homologs. Insect Biochem. Mol. Biol. 33, 1049-1060. doi: 10.1016/S09651748(03)00123-1

Jiang, R., Kim, E. H., Gong, J. H., Kwon, H. M., Kim, C. H., Ryu, K. H., et al. (2009). Three pairs of protease-serpin complexes cooperatively regulate the insect innate immune responses. J. Biol. Chem. 284, 35652-35658. doi: 10.1074/jbc.M109.071001

Kanost, M. R. (1999). Serine proteinase inhibitors in arthropod immunity. Dev. Comp. Immunol. 23, 291-301.

Kanost, M. R., and Gorman, M. J. (2008). "Phenoloxidases in insect immunity," in Insect Immunology, ed N. Beckage (San Diego, CA: Academic Press \& Elsevier), 69-96.

Kanost, M. R., Jiang, H., and Yu, X. Q. (2004). Innate immune responses of a lepidopteran insect, Manduca sexta. Immunol. Rev. 198, 97-105. doi: 10.1111/j.0105-2896.2004.0121.x

Karlsson, C., Korayem, A. M., Scherfer, C., Loseva, O., Dushay, M. S., and Theopold, U. (2004). Proteomic analysis of the Drosophila larval hemolymph clot. J. Biol. Chem. 279, 52033-52041. doi: 10.1074/jbc.M408220200

Kim, M. S., Baek, M. J., Lee, M. H., Park, J. W., Lee, S. Y., Soderhall, K., et al. (2002). A new easter-type serine protease cleaves a masquerade-like protein during prophenoloxidase activation in Holotrichia diomphalia larvae. J. Biol. Chem. 277, 39999-40004. doi: 10.1074/jbc.M205508200

Kirkwood, B. J. (2009). Albinism and its implications with vision. Insight 34, 13-16. Kopácek, P., Weise, C., and Götz, P. (1995). The prophenoloxidase from the wax moth Galleria mellonella: purification and characterization of the proenzyme. Insect Biochem. Mol. Biol. 25, 1081-1091. doi: 10.1016/0965-1748(95)00040-2

Kusche, K., Hembach, A., Hagner-Holler, S., Gebauer, W., and Burmester, T. (2003). Complete subunit sequences, structure and evolution of the $6 \times 6$-mer hemocyanin from the common house centipede, Scutigera coleoptrata. Eur. J. Biochem. 270, 2860-2868. doi: 10.1046/j.1432-1033.2003.03664.x

Kusche, K., Ruhberg, H., and Burmester, T. (2002). A hemocyanin from the Onychophora and the emergence of respiratory proteins. Proc. Natl. Acad. Sci. U.S.A. 99, 10545-10548. doi: 10.1073/pnas.152241199

Labrosse, C., Eslin, P., Doury, G., Drezen, J. M., and Poirie, M. (2005). Haemocyte changes in D. melanogaster in response to long gland components of the parasitoid wasp Leptopilina boulardi: a Rho-GAP protein as an important factor. J. Insect Physiol. 51, 161-170. doi: 10.1016/j.jinsphys.2004.10.004

Lai, S. C., Chen, C. C., and Hou, R. F. (2002). Immunolocalization of prophenoloxidase in the process of wound healing in the mosquito Armigeres subalbatus (Diptera: Culicidae). J. Med. Entomol. 39, 266-274. doi: 10.1603/0022-258539.2.266

Lavine, M. D., and Strand, M. R. (2002). Insect hemocytes and their role in immunity. Insect Biochem. Mol. Biol. 32, 1295-1309. doi: 10.1016/S09651748(02)00092-9

Lee, M. H., Osaki, T., Lee, J. Y., Baek, M. J., Zhang, R., Park, J. W., et al. (2004). Peptidoglycan recognition proteins involved in 1,3-beta-D-glucan-dependent prophenoloxidase activation system of insect. J. Biol. Chem. 279, 3218-3227. doi: 10.1074/jbc.M309821200

Lee, S. Y., Kwon, T. H., Hyun, J. H., Choi, J. S., Kawabata, S. I., Iwanaga, S., et al. (1998). In vitro activation of pro-phenoloxidase by two kinds of prophenoloxidase-activating factors isolated from hemolymph of coleopteran, Holotrichia diomphalia larvae. Eur. J. Biochem. 254, 50-57.

Lemaitre, B., and Hoffmann, J. (2007). The host defense of Drosophila melanogaster. Annu. Rev. Immunol. 25, 697-743. doi: 10.1146/annurev.immunol.25.022106. 141615

Li, B., and Paskewitz, S. M. (2006). A role for lysozyme in melanization of Sephadex beads in Anopheles gambiae. J. Insect Physiol. 52, 936-942. doi: 10.1016/j.jinsphys.2006.06.002

Li, J. S., Ruyl Kim, S., Christensen, B. M., and Li, J. (2005). Purification and primary structural characterization of prophenoloxidases from Aedes aegypti larvae. Insect Biochem. Mol. Biol. 35, 1269-1283. doi: 10.1016/j.ibmb.2005. 07.001

Li, J. Y., and Christensen, B. M. (1993). Involvement of L-tyrosine and phenol oxidase in the tanning of Aedes aegypti eggs. Insect Biochem Mol. Biol. 23, 739-748. doi: 10.1016/0965-1748(93)90048-W

Li, X., Ma, M., Liu, F., Chen, Y., Lu, A., Ling, Q. Z., et al. (2012). Properties of Drosophila melanogaster prophenoloxidases expressed in Escherichia coli. Dev. Comp. Immunol. 36, 648-656. doi: 10.1016/j.dci.2011.11.005

Li, Y., Wang, Y., Jiang, H., and Deng, J. (2009). Crystal structure of Manduca sexta prophenoloxidase provides insights into the mechanism of type 3 
copper enzymes. Proc. Natl. Acad. Sci. U.S.A. 106, 17002-17006. doi: 10.1073/pnas.0906095106

Ling, E., Shirai, K., Kanehatsu, R., and Kiguchi, K. (2005). Reexamination of phenoloxidase in larval circulating hemocytes of the silkworm, Bombyx mori. Tissue Cell 37, 101-107. doi: 10.1016/j.tice.2004.10.007

Ling, E., Shirai, K., Kanekatsu, R., Kiguchi, K., Kobayashi, Y., Funayama, T., et al. (2006). Contribution of circulating hemocytes to the regeneration of heavy ion beams $\left({ }^{12} \mathrm{C}^{5+}\right)$ irradiated hematopoietic organs in the silkworm, Bombyx mori, through the way of phagocytosis of injured cells after invasion. Dev. Comp. Immunol. 30, 531-543. doi: 10.1016/j.dci.2005.08.003

Ling, E., and Yu, X. Q. (2005). Prophenoloxidase binds to the surface of hemocytes and is involved in hemocyte melanization in Manduca sexta. Insect Biochem. Mol. Biol. 35, 1356-1366. doi: 10.1016/j.ibmb.2005.08.007

Liu, F., Chen, Y., Yang, B., Wang, J., Peng, Q., Shao, Q., et al. (2012). Drosophila melanogaster prophenoloxidases respond inconsistently to $\mathrm{Cu}^{2+}$ and have different activity in vitro. Dev. Comp. Immunol. 36, 619-628. doi: 10.1016/j.dci.2011.12.001

Liu, F., Xu, Q., Zhang, Q., Lu, A., Beerntsen, B. T., and Ling, E. (2013). Hemocytes and hematopoiesis in the silkworm, Bombyx mori. Invertebrate Surviv. J. 10, 102-109.

Liu, H., Jiravanichpaisal, P., Cerenius, L., Lee, B. L., Soderhall, I., and Soderhall, K. (2007). Phenoloxidase is an important component of the defense against Aeromonas hydrophila Infection in a crustacean, Pacifastacus leniusculus. J. Biol. Chem. 282, 33593-33598. doi: 10.1074/jbc.M706113200

Lu, A., Li, X., Hillyer, J. F., Beerntsen, B. T., Soderhall, K., and Ling, E. (2014a). Recombinant Drosophila prophenoloxidase 1 is sequentially cleaved by alphachymotrypsin during in vitro activation. Biochimie 102, 154-165. doi: 10.1016/ j.biochi.2014.03.007

Lu, A., Peng, Q., and Ling, E. (2014b). Formation of disulfide bonds in insect prophenoloxidase enhances immunity through improving enzyme activity and stability. Dev. Comp. Immunol. 44, 351-358. doi: 10.1016/j.dci.2014.01.011

Lu, Z., Beck, M. H., Wang, Y., Jiang, H., and Strand, M. R. (2008). The viral protein Egf1.0 is a dual activity inhibitor of prophenoloxidase-activating proteinases 1 and 3 from Manduca sexta. J. Biol. Chem. 283, 21325-21333. doi: 10.1074/jbc.M801593200

Luo, H., Hanratty, W. P., and Dearolf, C. R. (1995). An amino acid substitution in the Drosophila hopTum-l Jak kinase causes leukemia-like hematopoietic defects. EMBO J. 14, 1412-1420.

Marinotti, O., Ngo, T., Kojin, B. B., Chou, S. P., Nguyen, B., Juhn, J., et al. (2014). Integrated proteomic and transcriptomic analysis of the Aedes aegypti eggshell. BMC Dev. Biol. 14:15. doi: 10.1186/1471-213x-14-15

Mayer, A. M. (2006). Polyphenol oxidases in plants and fungi: going places? A review. Phytochemistry 67, 2318-2331. doi: 10.1016/j.phytochem.2006.08.006

Michel, K., Budd, A., Pinto, S., Gibson, T. J., and Kafatos, F. C. (2005). Anopheles gambiae SRPN2 facilitates midgut invasion by the malaria parasite Plasmodium berghei. EMBO Rep. 6, 891-897. doi: 10.1038/sj.embor.7400478

Miller, M. A., Pfeiffer, W., and Schwartz, T. (2010). "Creating the CIPRES Science Gateway for inference of large phylogenetic trees," in Gateway Computing Environments Workshop (GCE) (San Diego, CA), 1-8.

Nam, H. J., Jang, I. H., Asano, T., and Lee, W. J. (2008). Involvement of pro-phenoloxidase 3 in lamellocyte-mediated spontaneous melanization in Drosophila. Mol. Cells 26, 606-610.

Nam, H. J., Jang, I. H., You, H., Lee, K. A., and Lee, W. J. (2012). Genetic evidence of a redox-dependent systemic wound response via Hayan protease-phenoloxidase system in Drosophila. EMBO J. 31, 1253-1265. doi: 10.1038/emboj.2011.476

Nappi, A. J., and Christensen, B. M. (2005). Melanogenesis and associated cytotoxic reactions: applications to insect innate immunity. Insect Biochem. Mol. Biol. 35, 443-459. doi: 10.1016/j.ibmb.2005.01.014

Nappi, A. J., Frey, F., and Carton, Y. (2005). Drosophila serpin 27A is a likely target for immune suppression of the blood cell-mediated melanotic encapsulation response. J. Insect Physiol. 51, 197-205. doi: 10.1016/j.jinsphys.2004.10.013

Oetting, W. S., and King, R. A. (1999). Molecular basis of albinism: mutations and polymorphisms of pigmentation genes associated with albinism. Hum. Mutat. 13, 99-115. doi: 10.1002/(SICI)1098-1004(1999)13:2<99::AIDHUMU2 > 3.0.CO;2-C

Ohnishi, E., Dohke, K., and Ashida, M. (1970). Activation of prephenoloxidase. Arch. Biochem. Biophys. 139, 143-148. doi: 10.1016/0003-9861(70)90055-x

Paria, A., Greeshma, S. S., Chaudhari, A., Makesh, M., Purushothaman, C. S., and Rajendran, K. V. (2013). Nonspecific effect of double-stranded (ds) RNA on prophenoloxidase (proPO) expression in Penaeus monodon. Appl. Biochem. Biotechnol. 169, 281-289. doi: 10.1007/s12010-012-9964-5

Parkinson, N., Smith, I., Weaver, R., and Edwards, J. P. (2001). A new form of arthropod phenoloxidase is abundant in venom of the parasitoid wasp Pimpla hypochondriaca. Insect Biochem. Mol. Biol. 31, 57-63. doi: 10.1016/S09651748(00)00105-3

Piao, S., Kim, D., Won Park, J., Leul Lee, B., and Ha, N. C. (2005). Overexpression and preliminary $\mathrm{X}$-ray crystallographic analysis of prophenoloxidase activating factor II, a clip domain family of serine proteases. Biochim. Biophys. Acta 1752, 103-106. doi: 10.1016/j.bbapap.2005.05.008

Rajagopal, R., Thamilarasi, K., Venkatesh, G. R., Srinivas, P., and Bhatnagar, R. K. (2005). Immune cascade of Spodoptera litura: cloning, expression, and characterization of inducible prophenol oxidase. Biochem. Biophys. Res. Commun. 337, 394-400. doi: 10.1016/j.bbrc.2005.09.057

Ramet, M., Lanot, R., Zachary, D., and Manfruelli, P. (2002). JNK signaling pathway is required for efficient wound healing in Drosophila. Dev. Biol. 241, 145-156. doi: 10.1006/dbio.2001.0502

Rao, X. J., Ling, E., and Yu, X. Q. (2010). The role of lysozyme in the prophenoloxidase activation system of Manduca sexta: an in vitro approach. Dev. Comp. Immunol. 34, 264-271. doi: 10.1016/j.dci.2009.10.004

Rizki, T. M., Rizki, R. M., and Bellotti, R. A. (1985). Genetics of a Drosophila phenoloxidase. Mol. Gen. Genet. 201, 7-13. doi: 10.1007/BF00397978

Ross, J., Jiang, H., Kanost, M. R., and Wang, Y. (2003). Serine proteases and their homologs in the Drosophila melanogaster genome: an initial analysis of sequence conservation and phylogenetic relationships. Gene 304, 117-131. doi: 10.1016/S0378-1119(02)01187-3

Rund, S. S., Hou, T. Y., Ward, S. M., Collins, F. H., and Duffield, G. E. (2011). Genome-wide profiling of diel and circadian gene expression in the malaria vector Anopheles gambiae. Proc. Natl. Acad. Sci. U.S.A. 108, E421-E430. doi: 10.1073/pnas.1100584108

Sakamoto, M., Ohta, M., Suzuki, A., Takase, H., Yoshizawa, Y., Kitami, M., et al. (2011). Localization of the serine protease homolog BmSPH-1 in nodules of E. coli-injected Bombyx mori larvae and functional analysis of its role in nodule melanization. Dev. Comp. Immunol. 35, 611-619. doi: 10.1016/j.dci.2011 01.003

Scherfer, C., Tang, H., Kambris, Z., Lhocine, N., Hashimoto, C., and Lemaitre, B. (2008). Drosophila Serpin-28D regulates hemolymph phenoloxidase activity and adult pigmentation. Dev. Biol. 323, 189-196. doi: 10.1016/j.ydbio.2008.08.030

Schwarzenbach, G. A., and Ward, P. I. (2006). Responses to selection on phenoloxidase activity in yellow dung flies. Evolution 60, 1612-1621. doi: 10.1111/j.00143820.2006.tb00506.x

Sendovski, M., Kanteev, M., Ben-Yosef, V. S., Adir, N., and Fishman, A. (2011). First structures of an active bacterial tyrosinase reveal copper plasticity. J. Mol. Biol. 405, 227-237. doi: 10.1016/j.jmb.2010.10.048

Sevier, C. S., and Kaiser, C. A. (2002). Formation and transfer of disulphide bonds in living cells. Nat. Rev. Mol. Cell Biol. 3, 836-847. doi: 10.1038/nrm954

Shang, Y., Duan, Z., Huang, W., Gao, Q., and Wang, C. (2012). Improving UV resistance and virulence of Beauveria bassiana by genetic engineering with an exogenous tyrosinase gene. J. Invertebr. Pathol. 109, 105-109. doi: 10.1016/j.jip.2011.10.004

Shao, Q., Yang, B., Xu, Q., Li, X., Lu, Z., Wang, C., et al. (2012). Hindgut innate immunity and regulation of fecal microbiota through melanization in insects. J. Biol. Chem. 287, 14270-14279. doi: 10.1074/jbc.M112.354548

Shin, S. W., Zou, Z., and Raikhel, A. S. (2011). A new factor in the Aedes aegypti immune response: CLSP2 modulates melanization. EMBO Rep. 12, 938-943. doi: 10.1038/embor.2011.130

Shrestha, S., and Kim, Y. (2008). Eicosanoids mediate prophenoloxidase release from oenocytoids in the beet armyworm Spodoptera exigua. Insect Biochem. Mol. Biol. 38, 99-112. doi: 10.1016/j.ibmb.2007.09.013

Singh, S., Malhotra, A. G., Pandey, A., and Pandey, K. M. (2013). Computational model for pathway reconstruction to unravel the evolutionary significance of melanin synthesis. Bioinformation 9, 94-100. doi: 10.6026/97320630009094

Söderhäll, K., and Smith, V. J. (1983). Separation of the haemocyte populations of Carcinus maenas and other marine decapods, and prophenoloxidase distribution. Dev. Comp. Immunol. 7, 229-239. doi: 10.1016/0145-305x(83) 90004-6

Strand, M. R. (2008). The insect cellular immune response. Insect Sci. 15, 1-14. doi: 10.1111/j.1744-7917.2008.00183.x 
Sugumaran, M., and Nellaiappan, K. (2000). Characterization of a new phenoloxidase inhibitor from the cuticle of Manduca sexta. Biochem. Biophys. Res. Commun. 268, 379-383. doi: 10.1006/bbrc.2000.2138

Takehana, A., Katsuyama, T., Yano, T., Oshima, Y., Takada, H., Aigaki, T., et al. (2002). Overexpression of a pattern-recognition receptor, peptidoglycanrecognition protein-LE, activates imd/relish-mediated antibacterial defense and the prophenoloxidase cascade in Drosophila larvae. Proc. Natl. Acad. Sci. U.S.A. 99, 13705-13710. doi: 10.1073/pnas.212301199

Tang, H. (2009). Regulation and function of the melanization reaction in Drosophila. Fly (Austin) 3, 105-111. doi: 10.4161/fly.3.1.7747

Tokura, A., Fu, G. S., Sakamoto, M., Endo, H., Tanaka, S., Kikuta, S., et al. (2014). Factors functioning in nodule melanization of insects and their mechanisms of accumulation in nodules. J. Insect Physiol. 60, 40-49. doi: 10.1016/j.jinsphys.2013.11.003

Tsao, I. Y., Christensen, B. M., and Chen, C. C. (2010). Armigeres subalbatus (Diptera: Culicidae) prophenoloxidase III is required for mosquito cuticle formation: ultrastructural study on dsRNA-knockdown mosquitoes. J. Med. Entomol. 47, 495-503. doi: 10.1603/me08114

Tsao, I. Y., Lin, U. S., Christensen, B. M., and Chen, C. C. (2009). Armigeres subalbatus prophenoloxidase III: cloning, characterization and potential role in morphogenesis. Insect Biochem. Mol. Biol. 39, 96-104. doi: 10.1016/j.ibmb.2008.10.007

Tsukamoto, T., Ichimaru, Y., Kanegae, N., Watanabe, K., Yamaura, I., Katsura, Y., et al. (1992). Identification and isolation of endogenous insect phenoloxidase inhibitors. Biochem. Biophys. Res. Commun. 184, 86-92.

van Holde, K. E., and Miller, K. I. (1995). Hemocyanins. Adv. Protein Chem. 47, $1-81$.

Wang, B., Kang, Q., Lu, Y., Bai, L., and Wang, C. (2012). Unveiling the biosynthetic puzzle of destruxins in Metarhizium species. Proc. Natl. Acad. Sci. U.S.A. 109, 1287-1292. doi: 10.1073/pnas.1115983109

Wang, C. L., Wang, Z. X., Kariuki, M. M., Ling, Q. Z., Kiguchi, K., and Ling, E. J. (2010). Physiological functions of hemocytes newly emerged from the cultured hematopoietic organs in the silkworm, Bombyx mori. Insect Sci. 17, 7-20. doi: 10.1111/j.1744-7917.2009.01288.x

Wang, Y., and Jiang, H. (2004). Prophenoloxidase (proPO) activation in Manduca sexta: an analysis of molecular interactions among proPO, proPO-activating proteinase-3, and a cofactor. Insect Biochem. Mol. Biol. 34, 731-742. doi: 10.1016/j.ibmb.2004.03.008

Wang, Y., and Jiang, H. (2006). Interaction of beta-1,3-glucan with its recognition protein activates hemolymph proteinase 14 , an initiation enzyme of the prophenoloxidase activation system in Manduca sexta. J. Biol. Chem. 281, 9271-9278. doi: 10.1074/jbc.M513797200

Wang, Z., Lu, A., Li, X., Shao, Q., Beerntsen, B. T., Liu, C., et al. (2011). A systematic study on hemocyte identification and plasma prophenoloxidase from Culex pipiens quinquefasciatus at different developmental stages. Exp. Parasitol. 127, 135-141. doi: 10.1016/j.exppara.2010.07.005

Waterhouse, R. M., Kriventseva, E. V., Meister, S., Xi, Z., Alvarez, K. S., Bartholomay, L. C., et al. (2007). Evolutionary dynamics of immune-related genes and pathways in disease-vector mosquitoes. Science 316, 1738-1743. doi: $10.1126 /$ science. 1139862

Willott, E., Wang, X. Y., and Wells, M. A. (1989). cDNA and gene sequence of Manduca sexta arylphorin, an aromatic amino acid-rich larval serum protein. Homology to arthropod hemocyanins. J. Biol. Chem. 264, 19052-19059.

Yang, B., Lu, A., Peng, Q., Ling, Q. Z., and Ling, E. (2013). Activity of fusion prophenoloxidase-GFP and its potential applications for innate immunity study. PLoS ONE 8:e64106. doi: 10.1371/journal.pone.0064106

Yasuhara, Y., Koizumi, Y., Katagiri, C., and Ashida, M. (1995). Reexamination of properties of prophenoloxidase isolated from larval hemolymph of the silkworm Bombyx mori. Arch. Biochem. Biophys. 320, 14-23. doi: 10.1006/abbi. 1995.1337

Yoshida, H., and Ashida, M. (1986). Microbial activation of two serine enzymes and prophenoloxidase in the plasma fraction of hemolymph of the silkworm, Bombyx mori. Insect Biochem. 16, 539-545.

Yu, X. Q., Gan, H., and Kanost, M. R. (1999). Immulectin, an inducible Ctype lectin from an insect, Manduca sexta, stimulates activation of plasma prophenol oxidase. Insect Biochem. Mol. Biol. 29, 585-597. doi: 10.1016/S09651748(99)00036-3

Yu, X. Q., Jiang, H., Wang, Y., and Kanost, M. R. (2003). Nonproteolytic serine proteinase homologs are involved in prophenoloxidase activation in the tobacco hornworm, Manduca sexta. Insect Biochem. Mol. Biol. 33, 197-208. doi: 10.1016/s0965-1748(02)00191-1

Yu, X. Q., Zhu, Y. F., Ma, C., Fabrick, J. A., and Kanost, M. R. (2002). Pattern recognition proteins in Manduca sexta plasma. Insect Biochem. Mol. Biol. 32, 1287-1293. doi: 10.1016/S0965-1748(02)00091-7

Zhang, X., Zheng, Y., Jagadeeswaran, G., Ren, R., Sunkar, R., and Jiang, H. (2014). Identification of conserved and novel microRNAs in Manduca sexta and their possible roles in the expression regulation of immunity-related genes. Insect Biochem. Mol. Biol. 47, 12-22. doi: 10.1016/j.ibmb.2014.01.008

Zhao, M., Soderhall, I., Park, J. W., Ma, Y. G., Osaki, T., Ha, N. C., et al. (2005). A novel $43-\mathrm{kDa}$ protein as a negative regulatory component of phenoloxidase-induced melanin synthesis. J. Biol. Chem. 280, 24744-24751. doi: 10.1074/jbc.M504173200

Zhao, P., Li, J., Wang, Y., and Jiang, H. (2007). Broad-spectrum antimicrobial activity of the reactive compounds generated in vitro by Manduca sexta phenoloxidase. Insect Biochem. Mol. Biol. 37, 952-959. doi: 10.1016/j.ibmb.2007.05.001

Zou, Z., and Jiang, H. (2005). Manduca sexta serpin-6 regulates immune serine proteinases PAP-3 and HP8. cDNA cloning, protein expression, inhibition kinetics, and function elucidation. J. Biol. Chem. 280, 14341-14348. doi: 10.1074/jbc.M500570200

Zou, Z., Shin, S. W., Alvarez, K. S., Bian, G., Kokoza, V., and Raikhel, A. S. (2008). Mosquito RUNX4 in the immune regulation of PPO gene expression and its effect on avian malaria parasite infection. Proc. Natl. Acad. Sci. U.S.A. 105, 18454-18459. doi: 10.1073/pnas.0804658105

Zou, Z., Shin, S. W., Alvarez, K. S., Kokoza, V., and Raikhel, A. S. (2010). Distinct melanization pathways in the mosquito Aedes aegypti. Immunity 32, 41-53. doi: 10.1016/j.immuni.2009.11.011

Zou, Z., Wang, Y., and Jiang, H. (2005). Manduca sexta prophenoloxidase activating proteinase-1 (PAP-1) gene: organization, expression, and regulation by immune and hormonal signals. Insect Biochem. Mol. Biol. 35, 627-636. doi: 10.1016/j.ibmb.2005.02.004

Conflict of Interest Statement: The authors declare that the research was conducted in the absence of any commercial or financial relationships that could be construed as a potential conflict of interest.

Received: 24 April 2014; accepted: 17 June 2014; published online: 11 July 2014. Citation: Lu A, Zhang Q, Zhang J, Yang B, Wu K, Xie W, Luan Y-X and Ling E (2014) Insect prophenoloxidase: the view beyond immunity. Front. Physiol. 5:252. doi: 10.3389/fphys.2014.00252

This article was submitted to Integrative Physiology, a section of the journal Frontiers in Physiology.

Copyright (c) 2014 Lu, Zhang, Zhang, Yang, Wu, Xie, Luan and Ling. This is an openaccess article distributed under the terms of the Creative Commons Attribution License (CC BY). The use, distribution or reproduction in other forums is permitted, provided the original author(s) or licensor are credited and that the original publication in this journal is cited, in accordance with accepted academic practice. No use, distribution or reproduction is permitted which does not comply with these terms. 